\title{
Science goals and mission concept for the future exploration of Titan and Enceladus
}

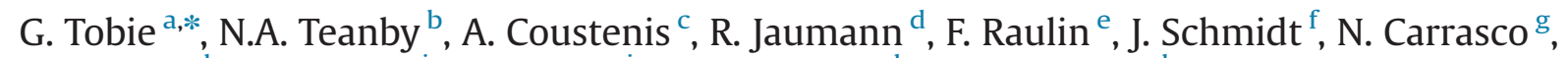
A.J. Coates ${ }^{\text {h }}$, D. Cordier ${ }^{i}$, R. De Kok ${ }^{\mathrm{j}}$, W.D. Geppert ${ }^{\mathrm{k}}$, J.-P. Lebreton ${ }^{1}$, A. Lefevre ${ }^{\mathrm{a}}$, T.A. Livengood ${ }^{\mathrm{m}}$, K.E. Mandt ${ }^{\mathrm{n}}$, G. Mitri ${ }^{\mathrm{a}}$, F. Nimmo ${ }^{\mathrm{o}}$, C.A. Nixon ${ }^{\mathrm{m}}$, L. Norman ${ }^{\mathrm{p}}$, R.T. Pappalardo ${ }^{\text {q, F. Postberg }}{ }^{\mathrm{r}}$, S. Rodriguez ${ }^{\text {s }}$, D. Schulze-Makuch ${ }^{\mathrm{t}}$, J.M. Soderblom ${ }^{\mathrm{u}}$, A. Solomonidou ${ }^{\text {c,v }}$, K. Stephan ${ }^{\text {d }}$, E.R. Stofan ${ }^{\text {m }}$, E.P. Turtle ${ }^{\mathrm{w}}$, R.J. Wagner ${ }^{\mathrm{d}}$, R.A. West ${ }^{\mathrm{q}}$, J.H. Westlake ${ }^{\mathrm{w}}$

\footnotetext{
${ }^{a}$ Laboratoire de Planétologie et Géodynamique de Nantes, University of Nantes, CNRS, UMR-6112, 44322 Nantes cedex, France

${ }^{\mathrm{b}}$ School of Earth Sciences, University of Bristol, Wills Memorial Building, Queen's Road, Bristol BS8 1RJ, UK

${ }^{\mathrm{c}}$ LESIA-Observatoire de Paris, CNRS, Université Paris 6, Université Paris-Diderot, 5 place Jules Janssen, 92195 Meudon, France

${ }^{\mathrm{d}}$ DLR, Institute of Planetary Research, Berlin, Germany

e Univ Paris Est Creteil, CNRS, UMR 7583, Lab Interuniv Syst Atmospher, IPSL, F-94010 Creteil, France

${ }^{\mathrm{f}}$ Univ Potsdam, D-14469 Potsdam, Germany

${ }^{\mathrm{g}}$ Univ Paris 06, Univ Versailles St Quentin, CNRS, LATMOS, F-78280 Guyancourt, France

${ }^{\mathrm{h}}$ Univ Coll London, Mullard Space Sci Lab, Dorking RH5 6NT, Surrey, England

${ }^{\mathrm{i}}$ Univ Franche Comte, Inst UTINAM, CNRS INSU, UMR 6213, Observ Sci Univers THETA, F-25030 Besancon, France

${ }^{j}$ SRON Netherlands Institute for Space Research, Sorbonnelaan 2, 3584 CA Utrecht, Netherlands

${ }^{\mathrm{k}}$ Stockholm Univ, Dept Phys, SE-10691 Stockholm, Sweden

${ }^{1}$ European Space Agcy, Estec, NL-2200 AG Noordwijk, Netherlands

${ }^{\mathrm{m}}$ NASA Goddard Space Flight Center, Greenbelt, MD, USA

${ }^{n}$ SW Res Inst, Space \& Sci Engn Div, San Antonio, TX 78238, USA

${ }^{\circ}$ Univ Calif Santa Cruz, Dept Earth \& Planetary Sci, Santa Cruz, CA 95064 USA

P UCL, Dept Space \& Climate Phys, Inst Origins, London WC1E 6BT, England

${ }^{\mathrm{q}}$ Jet Propulsion Laboratory, California Institute of Technology, Pasadena, CA, 91109 USA

${ }^{\mathrm{r}}$ Heidelberg Univ, Inst Earth Sci, D-69120 Heidelberg, Germany

${ }^{\mathrm{s}}$ Univ Paris 07, Lab AIM, CNRS, CEA, Ctr Orne Merisiers, F-91191 Gif Sur Yvette, France

${ }^{\mathrm{t}}$ Washington State Univ, Pullman, WA 99163, USA

${ }^{u}$ Dept. Earth, Atmospheric and Planetary Sciences, MIT, Cambridge, MA 02139, USA

${ }^{v}$ Univ Athens, Dept Geol \& Geoenvironm, Athens 15784, Greece

w Johns Hopkins Univ, Appl Phys Lab, Dept Space, Laurel, MD 20723, USA
}

\section{A R T I C L E I N F O}

\section{Article history:}

Received 31 December 2013

Received in revised form

23 September 2014

Accepted 6 October 2014

Available online 28 October 2014

\section{Keywords:}

Titan

Enceladus

Atmosphere

Surface

Ocean

Interior

Missions

\begin{abstract}
A B S T R A C T
Saturn's moons, Titan and Enceladus, are two of the Solar System's most enigmatic bodies and are prime targets for future space exploration. Titan provides an analogue for many processes relevant to the Earth, more generally to outer Solar System bodies, and a growing host of newly discovered icy exoplanets. Processes represented include atmospheric dynamics, complex organic chemistry, meteorological cycles (with methane as a working fluid), astrobiology, surface liquids and lakes, geology, fluvial and aeolian erosion, and interactions with an external plasma environment. In addition, exploring Enceladus over multiple targeted flybys will give us a unique opportunity to further study the most active icy moon in our Solar System as revealed by Cassini and to analyse in situ its active plume with highly capable instrumentation addressing its complex chemistry and dynamics. Enceladus' plume likely represents the most accessible samples from an extra-terrestrial liquid water environment in the Solar system, which has far reaching implications for many areas of planetary and biological science. Titan with its massive atmosphere and Enceladus with its active plume are prime planetary objects in the Outer Solar System to perform in situ investigations. In the present paper, we describe the science goals and key measurements to be performed by a future exploration mission involving a Saturn-Titan orbiter and a
\end{abstract}

\footnotetext{
* Corresponding author.

E-mail addresses: gabriel.tobie@univ-nantes.fr (G. Tobie), n.teanby@bristol.ac.uk (N.A. Teanby).
} 
Titan balloon, which was proposed to ESA in response to the call for definition of the science themes of the next Large-class mission in 2013. The mission scenario is built around three complementary science goals: (A) Titan as an Earth-like system; (B) Enceladus as an active cryovolcanic moon; and (C) Chemistry of Titan and Enceladus - clues for the origin of life. The proposed measurements would provide a step change in our understanding of planetary processes and evolution, with many orders of magnitude improvement in temporal, spatial, and chemical resolution over that which is possible with CassiniHuygens. This mission concept builds upon the successes of Cassini-Huygens and takes advantage of previous mission heritage in both remote sensing and in situ measurement technologies.

(c) 2014 Elsevier Ltd. All rights reserved.

\section{Introduction}

The Cassini-Huygens mission, which has been in orbit around Saturn since July 2004 and released the Huygens probe that landed on Titan's surface on January 14, 2005, has revealed Titan and Enceladus to be enigmatic objects - introducing extraordinary challenges for geologists, astrobiologists, organic chemists, and planetologists. Titan, Saturn's largest satellite, is unique in the Solar System with its extensive atmosphere made mostly of $\mathrm{N}_{2}$, with a column density 10 times that of Earth's atmosphere. The presence of a few per cent methane provides the basis for rich organic chemistry, leading to production of complex CHON compounds from the upper atmosphere down to the surface (e.g. Israël et al., 2005; Waite et al., 2007; Bézard et al., 2014). Methane is close to its triple point on Titan, which gives rise to a methanological cycle analogous to the terrestrial hydrological cycle, characterized by cloud activity, precipitation, river networks and lakes (e.g. Tomasko et al., 2005; Stofan et al., 2007; Rodriguez et al., 2009). Exploring Titan in greater detail than ever possible with Cassini-Huygens offers the possibility to study physical processes analogous to those shaping the Earth's landscape, where methane takes on water's role, and to analyse complex chemical processes that may have prebiotic implications (e.g. Raulin et al., 2012).

The discovery of jets of water vapor and ice grains emanating from Enceladus' south pole in 2005 is one of the major highlights of the Cassini-Huygens mission (e.g. Dougherty et al., 2006; Porco et al., 2006; Spahn et al., 2006; Waite et al., 2006; Spencer et al., 2009). Despite its small size (10 times smaller than Titan), Enceladus is the most active moon of the Saturnian system. Although geyser-like plumes have been reported on Triton (Soderblom et al., 1990) and more recently transient water vapor activity around Europa (Roth et al., 2014), Enceladus is the only one proven to have current endogenic activity. The jets, which form a huge plume of vapor and ice grains above Enceladus' south pole, are associated with abnormally elevated heat flow along tectonic ridges, called 'Tiger stripes'. Sampling of the plume by Cassini's instruments revealed the presence of water vapor, organics and salt-rich ice grains (Hansen et al., 2008; Waite et al., 2009; Postberg et al., 2009, 2011), suggesting that the jet sources are connected to subsurface salt-water reservoirs (e.g. Postberg et al., 2011). The surprising activity of Enceladus provides a unique opportunity to analyse materials coming from its waterrich interior, potentially containing compounds of prebiotic interest, and to study today aqueous processes that may have been important on many other icy worlds in the past.

The objectives of the present paper is to present the science goals and mission concept that were defined in response to the ESA call for the definition of the science theme of the next L-class (L2/L3) missions of the Cosmic Vision programme and to discuss the possible next step in the exploration of these two moons. Here we focus on science goals that could be achieved from the combination of a Saturn-Titan orbiter and a Titan balloon. The science goals and key measurements that may be achieved from the combination of a Titan orbiter and a lake probe are described in a companion paper (Mitri et al., 2014). The mission scenario described here is built around three major science goals, which were identified as the highest priority for such a mission:

- Goal A: Understand how Titan functions as a world, in the same way that one would ask this question about Venus, Mars, and the Earth.

- Goal B: Characterize the present-day activity of Enceladus, to understand what processes power it and how it affects the Saturnian environment.

- Goal C: Determine the degree of chemical complexity on the two moons, to analyse complex chemical processes that may haveprebiotic implications.

These goals are explained in detail in Sections 2-4. In Section 5, we briefly discuss a possible mission concept and key measurements, and consider the technological issues involved in return to the Saturn system. Section 6 provides a brief conclusion and some perspectives for the preparation of future exploration mission projects.

\section{Science goal a: Titan as an earth-like system}

Titan is a complex world more like the Earth than any other: it is the only place besides Earth known to have a dense, predominantly nitrogen, atmosphere; it has an active climate and meteorological cycle where the working fluid - methane - behaves under Titan's conditions the way that water does on Earth; and its geology - from lakes and seas to broad river valleys and mountains - while carved in ice is, in its vast range of processes, again most like Earth. Beneath this panoply of terrestrial processes an ice crust floats atop what appears to be a liquid water ocean. Science Goal A seeks to understand how Titan functions as a world, in the same way that one would ask this question about Venus, Mars, and the Earth. How are the distinctions between Titan and other worlds in the Solar System understandable in the context of the complex interplay between geology, hydrology, meteorology, and aeronomy? Is Titan an analogue for some aspect of the Earth's history, past or future? Why is Titan endowed with an atmosphere when, for example, Jupiter's moon Ganymede, virtually identical in size and mass, is not? Although the Cassini-Huygens mission provided major advances for understanding the atmospheric and geological processes at work on Titan, many questions remain unanswered addressing these questions require future missions designed to explore these worlds.

\subsection{Titan's atmosphere}

\subsubsection{Meteorology and methane cycle}

Titan is the only body in the Solar System besides Earth with an active "hydrologic" cycle, featuring methane rather than water as the condensable fluid in clouds, rain, and surface reservoirs (lakes). Titan has an obliquity of $26.7^{\circ}$ ( similar to Earth) giving pronounced seasonal change during its 29.5-year orbit around the Sun. Cassini 
imaging shows that Titan's tropospheric clouds range from midlatitude streaks, equatorial bands and patches, and summer polar convective outbursts, to a long-lived high-altitude winter polar cap (Rodriguez et al., 2009, 2011; Le Mouélic et al., 2012, Fig. 1). Polar cloud activity appears to disappear as equinox approaches (Fig. 1). Occasional equinoctial tropical methane monsoons have been speculated and recent observations of an equatorial arrowshaped cloud (Turtle et al., 2011, Fig. 1) suggest an inter-tropical convergence zone following solar insolation maximum (Mitchell et al., 2011). Such storms and subsequent rainfall could explain the formation of equatorial fluvial surface erosion and intricate valley networks like those seen around the Huygens probe landing site (Tomasko et al., 2005, Fig. 2c).

Despite these major advances, Cassini's observations are limited by incomplete time coverage, due to the Saturn-centric orbit, which leads to a sporadic time series dependent on widely spaced Titan flybys/encounters. This makes it difficult to accurately assess global trends and seasonality in Titan's rapidly changing methane cycle. Continuous measurement of cloud distribution, characteristics, and evolution is now essential to constrain energy budgets, surface methane sources, and tropospheric circulation. It is unclear how often it rains on Titan, which determines erosion rates and how fluids are transferred around the globe. Investigating Titan's active meteorology will reveal the controlling factors that link surface and atmospheric interactions.

\subsubsection{Global dynamics, circulation, and seasonal change}

Titan provides a giant natural laboratory for testing Earth-based climate and general circulation models under different physical conditions. Much of Titan's general circulation, however, remains to be constrained - particularly above $500 \mathrm{~km}$, below $100 \mathrm{~km}$, within polar vortices, and in equatorial regions (Flasar et al., 2009). Measurements of circulation in these regions are important for constraining how strongly tropospheric and stratospheric circulation are coupled, whether the tropopause wind minimum and near-surface flow reversal observed by Huygens (Bird et al., 2005) are global features, and how thermal energy is redistributed in the upper atmosphere. A Titan orbiter would provide continuous coverage for remote sensing instruments and a regular series of radio occultations that would provide major advances. By comparing such measurements with legacy data from Voyager and Cassini, long-term climate trends could also be investigated.

Studying the seasonal variation of circulation patterns has been limited by the coverage available from each flyby, which is nonuniform and globally incomplete, but significant progress has been made. In addition to winds derived by Huygens probe radio tracking (Bird et al., 2005), there have also been cloud-tracking attempts, but these have been severely limited by Cassini's short flyby durations. Indirect measurements of the middle-atmospheric zonal winds have been derived from temperature fields via the thermal wind equation and vertical winds have been probed using chemical tracers and adiabatic heating (Teanby et al., 2008, 2009b, 2010b, 2012; Coustenis et al., 2010). Maps of atmospheric temperature and composition also show that Titan's atmospheric rotation axis is different from that of a solid body (Achterberg et al., 2008; Roman et al., 2009; Teanby et al., 2010a). The cause of this is currently unclear, but could be linked to thermal tides. Gravity waves appear to be an important and controlling feature of Titan's atmosphere and a major contributor to the super-rotation, but have only been directly profiled at a single point and a single season by the Huygens probe, so at present are very poorly constrained. Titan's detached haze varies in altitude from about $300 \mathrm{~km}$ to $500 \mathrm{~km}$ and is apparently synchronized to seasonal cycles (West et al., 2011) and reveals a strong coupling with the atmosphere dynamics (Cours et al., 2011). The nature of this coupling is still under debate, but the haze is clearly an important tracer of atmospheric dynamics in Titan's upper stratosphere. The vertical distribution of haze in the troposphere is also unknown and could provide nuclei for condensation. Further progress in all dynamical aspects of Titan's atmosphere now requires high temporal resolution monitoring from an orbiter.

\subsubsection{Temperature structure}

Titan's temperature structure and its evolution over seasonal timescales are essential for understanding climatic evolution, global circulation, photochemistry, and condensation processes. The chemical composition of Titan's atmosphere is similar to Earth's nitrogendominated atmosphere and both planets feature a distinct stratosphere. Titan's atmosphere is unique within the Solar System because it is so cold and extends to such high altitude, with evidence that upper atmospheric temperature is influenced by both magnetospheric plasma (external influence) (Westlake et al., 2011) and atmospheric waves (internal) (Hinson and Tyler, 1983), causing it to change rapidly (Snowden et al., 2013; Snowden and Yelle, 2014). Yet the existence of Titan's atmosphere appears relatively stable. Atmospheric escape (Yelle et al., 2008; Strobel, 2009) or irreversible photochemical conversion (Yung et al., 1984) are processes that could eliminate Titan's current atmosphere, although many aspects of these processes remain controversial (Bell et al., 2014). In any case, Titan's atmosphere is either begin replenished by processes not yet fully understood or

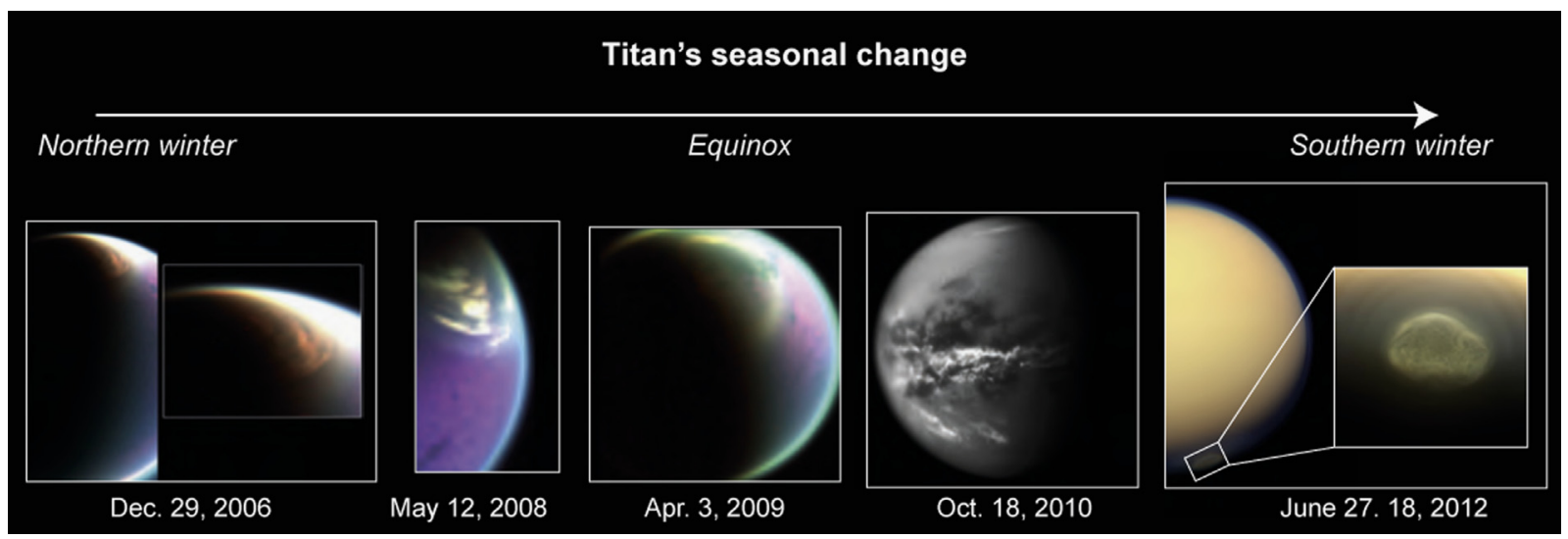

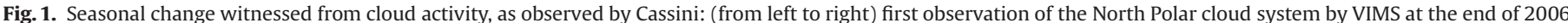

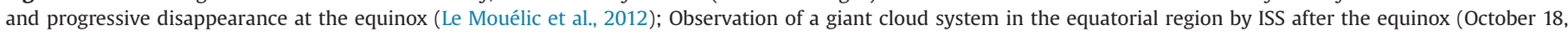

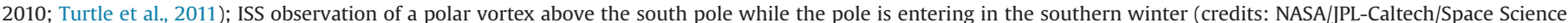
Institute). 
Titan's surface and interior

a

Dune fields and craters on the edge of Xanadu terrain

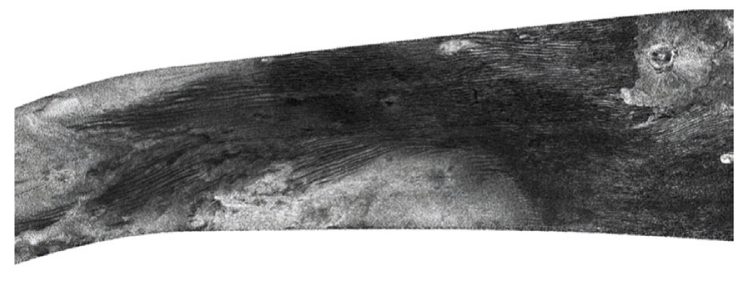

C

Channel networks in the vicinity of the Huygens landing site

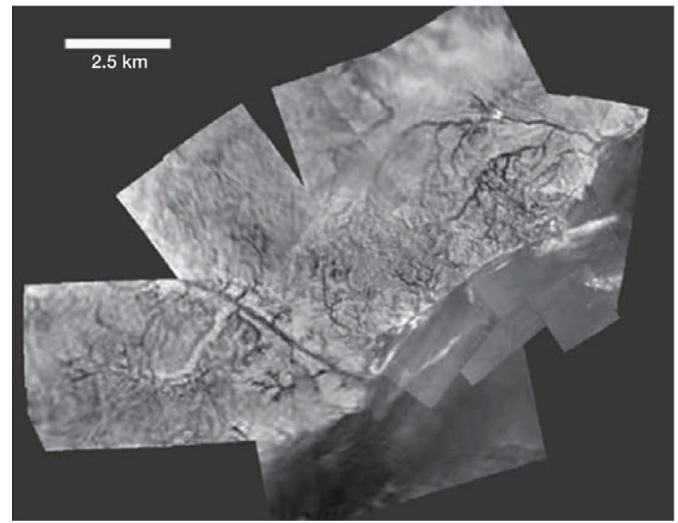

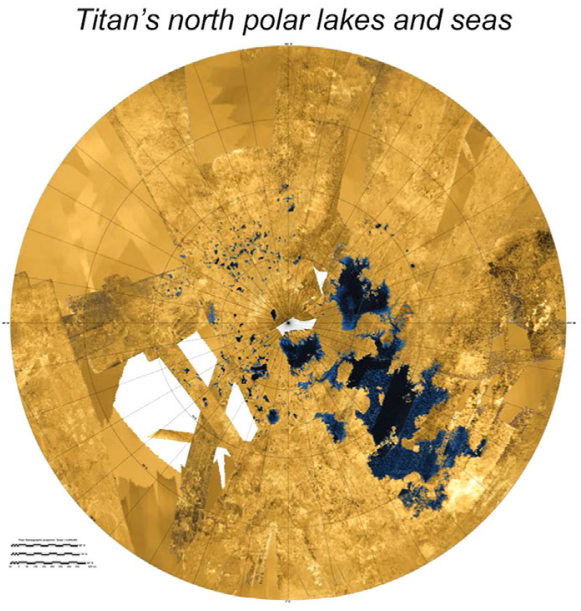

d

Clues for a cold viscous ice shell above a salty ocean

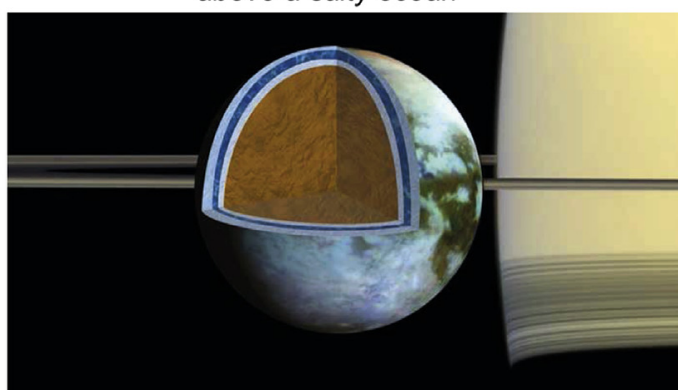

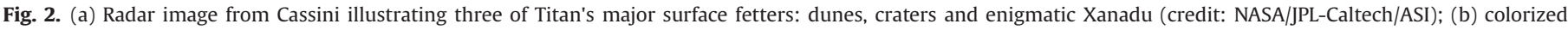

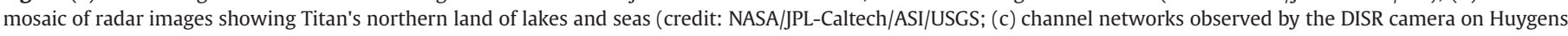

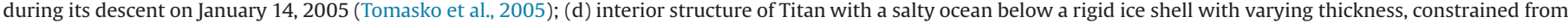
gravity and shape data (Mitri et al., 2014) (credit: NASA/JPL-Caltech/SSI/University of Arizona/University of Nantes).

else is being explored in a temporary state. A better understanding and more data on the chemistry of Titan's atmosphere and its interaction with the surface will enable us to solve this question.

Competition between absorbed ultraviolet and emitted infrared radiation creates Titan's pronounced Earth-like stratopause, which is not present on Mars or Venus, making Titan especially relevant for comparison with Earth. Although the single Huygens atmospheric profile suggests waves could be important above $500 \mathrm{~km}$ (Fulchignoni et al., 2005), there are serious gaps in our knowledge that Cassini will not be able to address. We have little information for the altitude ranges $0-100 \mathrm{~km}$ and $500-950 \mathrm{~km}$. These regions are important because many of Titan's trace species condense around $100 \mathrm{~km}$, whereas the $500-950 \mathrm{~km}$ region links the bulk neutral atmosphere to photochemical source regions. Additionally the location of the homopause on Titan has long been an issue of debate and has major implications for atmospheric escape rate (Strobel, 2009). Thermospheric temperatures strongly influence escape and are important for determining how the system as a whole operates and how or if equilibrium is maintained. Furthermore, a currently inaccessible region below $200 \mathrm{~km}$ within the winter polar vortex is a potential site for exotic chemistry on nitrile/hydrocarbon ices and could have parallels with Earth's Antarctic polar chemistry and polar stratospheric clouds (Flasar et al., 2005).

\subsubsection{Complex chemistry and haze formation}

A mission to Titan is the most effective way to study complex organic, inorganic and ionic chemistry at all altitudes, from formation of complex hydrocarbon species high in the atmosphere down through the bulk atmosphere. Currently formation of complex molecules, ions, and haze is poorly constrained. The present lack of constraints on the aerosol chemical composition precludes clear benchmarks for further synthetic organic solid studies in the laboratory (Cable et al., 2012; Gautier et al., 2014; Sebree et al., 2014; Westlake et al., 2014). A mission dedicated to Titan is essential to determine haze composition, how its formation in the ionosphere links to other levels, if its composition changes with altitude, how it affects climate, and its role in the methane cycle and surface composition, morphology and alteration.

Titan's atmosphere is rich in organic compounds sourced from a highly active photochemical cycle that begins in the ionosphere $(\sim 1000 \mathrm{~km})$ and influences the entire atmospheric column (Lavvas et al., 2008). Discovery of the extent of the chemical complexity of Titan's ionosphere was one of Cassini's major breakthroughs and encompasses neutral species, positive ions, and negative ions (Coates et al., 2007; Waite et al., 2007, Fig. 3a and b). Cassini found unexpected negative ions up to $13,800 \mathrm{u} / \mathrm{q}$ (Coates et al., 2007; Coates, 2009) and positive ions up to $\sim 1000 \mathrm{u}$ (Waite et al., 2007; Crary et al., 2009; Coates et al., 2010), implying that linked neutral-cation-anion chemistry could play a key role in haze formation (Lavvas et al., 2013). Some amount of nitrogen inclusion occurs in these compounds, but it is unclear how far into the chemical chains nitrogen prevails. Ion structures are at present unconstrained and could be chains, rings or even fullerenes, which may play a role transporting oxygen to the surface (Sittler et al., 2009). Furthermore, although Cassini's instruments have not yet detected molecules more complex than benzene $\left(\mathrm{C}_{6} \mathrm{H}_{6}\right)$ below $500 \mathrm{~km}$, recent laboratory work by Gudipati et al. (2013) showed that complex chemistry may be important throughout the entire atmospheric column, including both upper and lower atmospheric regions (Fig. 3c). 


\section{Titan's organic chemistry}

a Evidence for complex organic molecules and tholin formation at high altitudes $(\sim 1000 \mathrm{~km})$

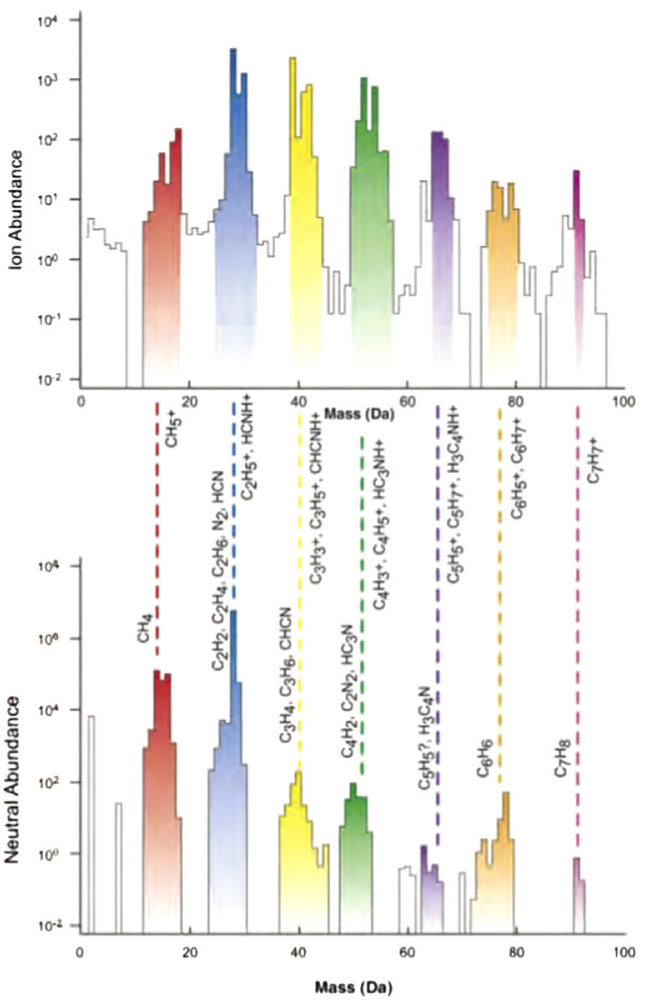

C Identification of numerous hydrocarbons, nitriles, and oxygen species between 100 and $200 \mathrm{~km}$

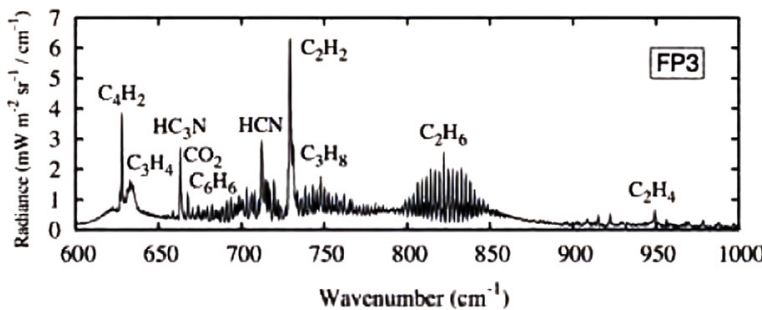

b Discovery of heavy negative ions
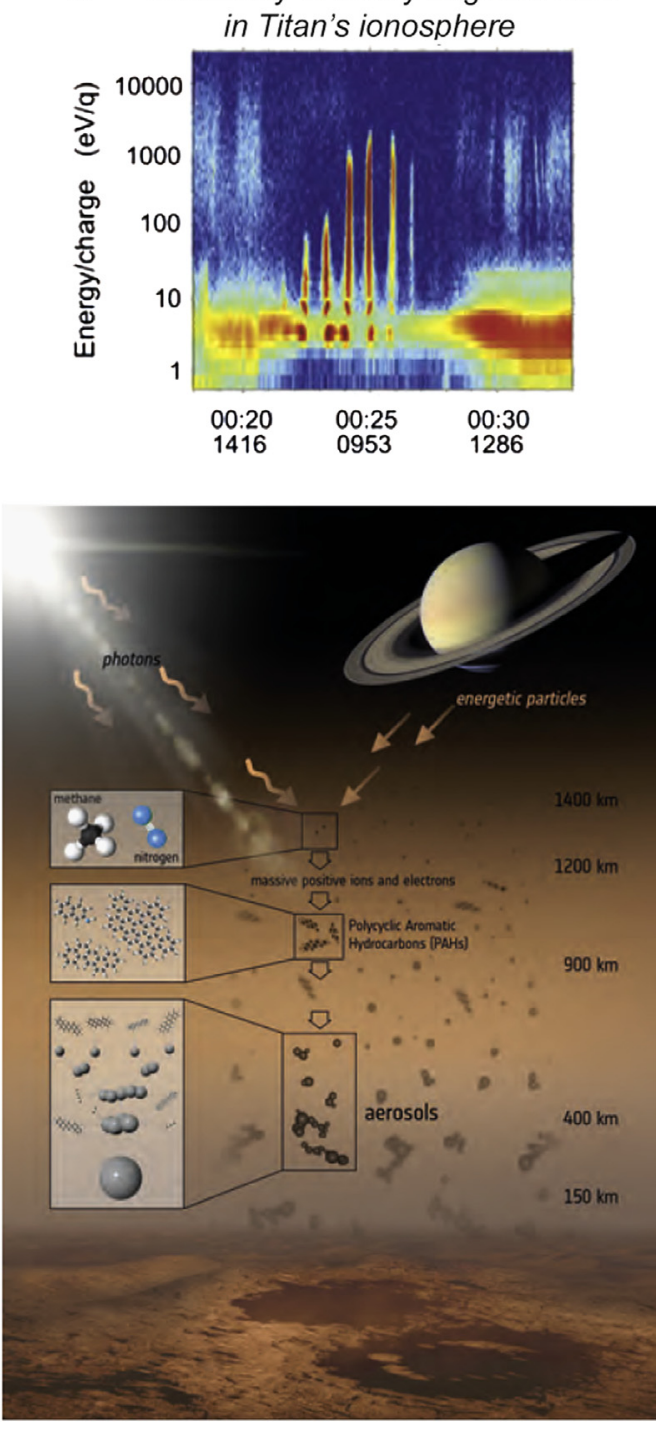

d The formation of Titan's photochemical haze

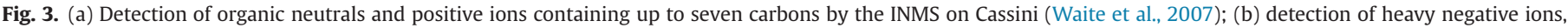

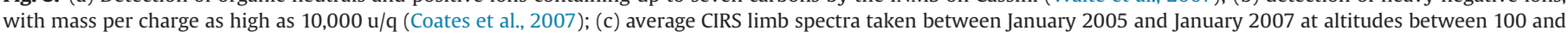

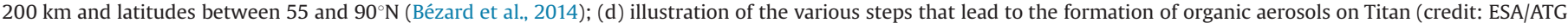
media lab).

\subsection{Titan's geology}

Titan's dense atmosphere is opaque at most visible and nearinfrared wavelengths and the surface is only visible using reflected sunlight at specific windows in the near infrared and at RADAR wavelengths. Prior to Cassini's arrival at Saturn in 2004, bright and dark features were observed in near-infrared images acquired by the Hubble Space Telescope and Earth-based telescopes (e.g. Coustenis et al., 2005). But the lack of spatial resolution precluded any geological interpretation. Observations performed by the Cassini RADAR, the Visual and Infrared Mapping Spectrometer (VIMS), and the Imaging Science Subsystem (ISS), have revealed a remarkably diverse Earth-like surface in terms of landforms and geologic features, indicating that Titan shares many characteristics with the Earth (e.g. Jaumann et al., 2009; Stephan et al., 2013, Fig. 2). Titan's landscapes are shaped by a variety of surficial processes including impact cratering, aeolian, fluvial and lacustrine processes, and also endogenic processes including cryovolcanism and tectonism.

\subsubsection{Impact craters}

A remarkable characteristic of Titan's surface is the relative paucity of impact craters - one of the many attributes it shares with the Earth - which indicates a relatively young and active surface (Jaumann et al., 2009; Wood et al., 2010; Neish and Lorenz, 2012). Wood et al. (2010) and Neish and Lorenz (2012) list a total of 60 possible impact craters using Cassini RADAR data (currently covering $\sim 33 \%$ of the surface) ranging from 3 to $445 \mathrm{~km}$ in diameter. Titan's craters appear in some ways morphologically different from those on airless icy satellites, perhaps due to effects of the atmosphere or subsurface liquids (Neish and Lorenz, 2014). 
Soderblom et al. (2010), for example, report an apparent fluidizedejecta blanket, similar in morphology to the bright crater outflows of Venus. With so few preserved craters, the age of Titan's surface remains uncertain and depends both on the cratering chronology model used and the sample set selected; estimates range from $\sim 200 \mathrm{Ma}$ to $\sim 1 \mathrm{Ga}$, depending on which crater scaling function is used (e.g. Neish and Lorenz, 2012).

\subsubsection{Aeolian features and processes}

Aeolian activity on Titan has proven to be one of the major forces at work, as is especially apparent at low latitudes. Almost half the terrain within $30^{\circ}$ of the equator is covered in dark (presumably organic-rich) streaks or dunes (e.g. Lorenz et al., 2006; Radebaugh et al., 2008, Fig. 2a). In a few of the best-imaged regions, these dunes are hundreds of kilometres long and $\sim 150 \mathrm{~m}$ high. Almost all appear to be linear dunes, a type common in the Arabian, Sahara, and Namib deserts on Earth, but rare on Mars. These types of dunes typically form in long-lived bidirectional wind regimes. A tidal wind origin has been proposed for Titan, but seasonal wind changes may also play a role. While it has not been demonstrated that these dunes are presently active, they are certainly young relative to other geologic features (cf. Radebaugh et al., 2008). Interestingly, dune morphologies suggest westerly surface winds, which seems a priori at odds with the Huygens wind measurements (cf. Bird et al., 2005; Tomasko et al., 2005).

\subsubsection{Fluvial features and processes}

Fluvial surface modification was evident at the Huygens landing site (Tomasko et al., 2005; Lorenz et al., 2008b; Jaumann et al., 2008, 2009, Fig. 2c). Not only were steeply incised channels a few kilometres long and $\sim 30 \mathrm{~m}$ across observed in the nearby bright highland (Perron et al., 2006; Jaumann et al., 2008), but the view from the probe after landing showed rounded cobbles characteristic of transport in a low-viscosity fluid (Tomasko et al., 2005). Radar-bright channels have been observed at low and midlatitudes (Lorenz et al., 2008b; Langhans et al., 2012), while channels incised to depths of several hundred meters are exposed elsewhere. At high latitudes radar-dark, meandering channels suggest a lower-energy environment where deposition of finegrained sediment occurs. Whether formation of these larger channels - some of which exceed a kilometre in width - and the large-scale flow features near the landing site (Soderblom et al., 2007; Jaumann et al., 2009) requires a different climate regime remains to be determined. The flow of methane rivers in an unsaturated atmosphere on Titan is analogous to the problem of ephemeral water flow on Mars and terrestrial deserts: determining whether the rivers dry out, freeze solid, or drain into subsurface alkanifers or ephemeral lakes and seas requires measurement of presently unknown meteorological factors.

\subsubsection{Lacustrine features and processes}

Extremely radar-dark features at Titan's high latitudes are consistent with liquid-filled lakes and seas ranging in size from less than $10 \mathrm{~km}^{2}$ to at least $100,000 \mathrm{~km}^{2}$ (Stofan et al., 2007 , Fig. 2b). A specular reflection observed in VIMS data also indicates surface liquids (Stephan et al., 2010; Soderblom et al., 2012). Although ethane has been detected as a component of the liquid (Brown et al., 2008), the composition remains largely uncertain (Cordier et al., 2012). The most recent radar analyses indicate that the lakes have a very smooth surface (Zebker et al., 2014) and are remarkably transparent (Mastrogiuseppe et al., 2014), suggesting that they are mostly composed of methane. Empty lakebeds have been detected (Stofan et al., 2007; Hayes et al., 2008) and the existence of evaporite deposits is suspected (Barnes et al., 2011). The morphology of boundaries between some lakes and their surroundings resembles a terrain flooded by liquids, with the dark material appearing to flood valleys between brighter hilly terrain and in some cases occupying networks of channels that feed into or out of the lakes. Other lakes (e.g., many of the smaller lakes at high northern latitudes and possibly Ontario Lacus in the south) appear to be formed by dissolution (e.g. Cornet et al., 2012). The Huygens landing site is littered with 1-10-cm-scale mostly rounded pebbles, implying they were tumbled and deposited by liquids feeding into a now dry lake bed from dendritic valley systems seen in the Huygens DISR images (Keller et al., 2008). Systematically determining the depths of the lakes, similar to what have been tentatively done with Cassini (e.g. Ventura et al., 2012; Mastrogiuseppe et al., 2014), is of high importance, both to constrain the total amount of liquid they contain, and to understand the underlying geological processes and "methanological" cycling that formed them.

\subsubsection{Endogenic activity}

Cryovolcanism is a process of particular interest at Titan, especially because of the astrobiological potential of liquid water erupting onto photochemically produced organic compound deposits, solid and liquid, accumulated at the surface through time (e.g. Fortes and Grindrod, 2006; Poch et al., 2012). Radiogenic heating in Titan's interior, possibly augmented by tidal heating, can provide enough heat to drive a substantial resurfacing rate (e.g. Tobie et al., 2006). Kinetically, cryovolcanism is much easier in the Saturnian system, where ammonia can facilitate the generation and rise of cryofluids through an ice crust, than in the Galilean satellites (e.g. Fortes et al., 2007). Several candidate sites of cryovolcanism have been identified in Cassini near-infrared VIMS and RADAR data (e.g. Lopes et al., 2013; Sohl et al., 2014). Evidence for active volcanism, however, is still debated (cf. Moore and Pappalardo, 2011), and the role of cryovolcanism on Titan is an important factor for understanding exchange processes between atmosphere, surface and interior. It thus needs further scrutiny.

The role tectonism plays on Titan is also not well understood. A number of large-scale linear features are seen optically (Porco et al., 2005). Some features on Titan are parts of the landscape morphology correlated to tectonics that are/were subsequently subjected to exogenous processes, surficial and/or atmospheric (Solomonidou et al., 2013). Such features include mountains (e.g. Radebaugh et al., 2007), ridges (e.g. Mitri et al., 2010), faults (e.g. Radebaugh et al., 2011), and canyons (e.g. Lopes et al., 2010). Radar imagery of some of these features has not helped in their interpretation and is not yet sufficiently widespread to evaluate tectonic patterns, although some linear mountain ranges (e.g. Radebaugh et al., 2007) have been detected, several forming a chevron pattern near the equator. Near-infrared imagery by Cassini VIMS has also shown long ridges (e.g. Soderblom et al., 2007; Jaumann et al., 2009). An outstanding mystery is the nature of the large bright terrain Xanadu and its adjoining counterpart Tsegihi. These areas are distinct optically, and they have unusual radar properties. SAR imagery shows Xanadu to be extremely rugged, and appeared to be an ancient large-scale feature reshaped by fluvial process (e.g. Langhans et al., 2013). However, processes at its origin still remain unclear.

\subsubsection{Evidence for a global internal ocean on Titan}

A series of geophysical measurements (gravity field, less et al., 2012; electric field, Béghin et al., 2012; obliquity, Baland et al., 2011, 2014; and shape, Nimmo and Bills, 2010; Mitri et al., 2014) performed by Cassini-Huygens indicate the presence of a global water ocean, likely salt-rich, a few $10 \mathrm{~s}$ to $>100 \mathrm{~km}$ below the surface (Fig. 2d). Measured tidal fluctuations in the gravity field are consistent with the existence of a decoupling water layer 
below the ice shell (Iess et al., 2012). The interpretation of gravity and topography data indicates that the thickness of the ice shell above the ocean should vary with latitude and longitude, implying that the ice shell is thermally conductive and has a high viscosity at present (Hemingway et al., 2013; Lefevre et al., 2014; Mitri et al., 2014). Moreover, the observed elevated tidal Love number and obliquity imply a dense ocean (Baland et al., 2014), which is consistent with a cold and salty ocean. Such an ocean, with an elevated concentration of ionic solutes, may also explain the electric field perturbation observed by Huygens and interpreted as a Schumann resonance (Béghin et al., 2012). The salt enrichment as well as the ${ }^{40} \mathrm{Ar}$ atmospheric abundance (Niemann et al., 2010) suggests an efficient leaching process and prolonged waterrock interactions. The chemical exchanges associated with waterrock interactions may be quantified by accurately measuring the ratio between radiogenic and non-radiogenic isotopes in noble gases (Ar, Ne, Kr, Xe) in Titan's atmosphere (Tobie et al., 2012). Further tidal monitoring from gravity, topography and rotation data along with magnetic and electric field measurements would provide key constraints on the physical properties of the ocean (depth, density, electric conductivity) as well as the ice shell (thickness, viscosity structure).

\section{Science goal B: Enceladus as an active cryovolcanic moon}

The detection of jets of water vapor and ice particles emanating from the south polar terrain of Enceladus is one of the major discoveries of the Cassini-Huygens mission (Fig. 4). This surprising activity has been studied by a suite of instruments onboard the Cassini spacecraft, analyzing the plume structure and the composition of the vapor and icy grain components (also called the dust in the following), their mass ratio, the speed and size distributions of the constituents, the interaction with the Saturnian corotational plasma, as well as the replenishment of the magnetosphere and $\mathrm{E}$ ring region with fresh plasma and dust particles. Science goal B seeks to further characterize the present-day activity of Enceladus, to understand what processes power it and how it affects the Saturnian environment.

Although geyser-like plumes and transient water vapor activity have been reported on Triton (Soderblom et al., 1990) and on Europa (Roth et al., 2014) respectively, Enceladus is the only icy world in the Solar System proven to have current endogenic activity. Triton's geysers are believed to be solar-driven (Brown et al., 1990; Kirk et al., 1990) and the origin of the transient water vapor emission above Europa's south pole are still unknown (Roth et al., 2014). The cryovolcanic activity of Enceladus offers a unique possibility to sample fresh material emerging from subsurface liquid water and to understand how exchanges with the interior controls surface activity. It provides us with an opportunity to study today, phenomena that may have been important in the past throughout the outer Solar System, when tidal effects and/or higher radiogenic heat fluxes could have powered eruptions, melting, and aqueous chemistry in a number of icy bodies.

\subsection{Enceladus' plume activity}

\subsubsection{Plume characteristics}

About $200 \mathrm{~kg} / \mathrm{s}$ of vapor is ejected from Enceladus' south pole at speeds exceeding $500 \mathrm{~m} / \mathrm{s}$ (Hansen et al., 2008), which is well above the escape velocity of $240 \mathrm{~m} / \mathrm{s}$. The gas is emitted in a broad, vertically extended plume with embedded, collimated and supersonic jets (Waite et al., 2006; Hansen et al., 2008, 2011). The dust plume also exhibits a broad component and localized jets (Porco et al., 2014, Fig. 4a), but it has a relatively small scale-height (Porco et al., 2006; Spahn et al., 2006; Schmidt et al., 2008), corresponding to slower mean ejection speeds on the order of $100 \mathrm{~m} / \mathrm{s}$. Schmidt et al. (2008) infer a dust production rate of 5$10 \%$ of the vapor production, although later photometric studies indicate a more massive dust plume (Hedman et al., 2009; Ingersoll and Ewald, 2011). A precise determination of the dustto-vapor ratio, and variability therein, is now crucial to better understand the physical mechanisms responsible for the activity.

In contrast to the gas plume, only a small fraction (1-5\%) of ejected icy dust exceeds the escape velocity of Enceladus and feeds the $\mathrm{E}$ ring. Most grains fall back on the surface in a characteristic global "snow" pattern (Kempf et al., 2010; Schenk et al., 2011). The size distribution of this dust was constrained from in situ measurements (Spahn et al., 2006) and infrared spectroscopy (Hedman et al., 2009) to roughly follow a power law (exponent -4), extending from the submicron range up to a few microns. Estimating accurately, both the fraction of particles falling back to the surface and the thickness of surface deposit, will provide essential information on the duration of plume activity.

\subsubsection{Gas and grain composition}

In situ measurements by Cassini INMS (Waite et al., 2006, 2009) showed that plume gas consists primarily of water vapor and about $\sim 5-10 \%$ other volatiles (Fig. $4 \mathrm{~b}$ ). The main volatile species are $\mathrm{CO}_{2}, \mathrm{NH}_{3}$ and a mixture of organic gases (Waite et al., 2009). Amongst the latter are lightweight molecules like methane, acetylene and propane, but recent measurements also indicate even higher molecular weight compounds with masses exceeding $100 \mathrm{u}$. and aromatic organics (Waite et al., 2011). A molecule with mass of $28 \mathrm{u}$., which could be attributed to $\mathrm{N}_{2}$, $\mathrm{CO}$ or $\mathrm{C}_{2} \mathrm{H}_{4}$, was also identified, but due to the lack of resolution, the ratio $\mathrm{CO} / \mathrm{N}_{2} /$ $\mathrm{C}_{2} \mathrm{H}_{4}$ cannot be constrained. This information is, however, essential in establishing the origin of the volatiles.

Analyzing the composition of particles in the $\mathrm{E}$ ring and directly in the plume with Cassini CDA, Postberg et al. $(2009,2011)$ found that nearly all grains contain at least small amounts of sodium (roughly on ppm level), while other grains show much larger fractions of sodium and potassium salts like $\mathrm{NaCl}, \mathrm{NaHCO}_{3}$ and $\mathrm{KCl}$ (Fig. 4c). The conclusion was that these salt-rich grains $(\sim 0.5-2 \%$ by mass of salts) must directly disperse from salt water. Moreover, the composition inferred by CDA matches the prediction of Zolotov (2007) for the composition of a subsurface ocean that is, or was, in contact with a pristine rocky core. Nanometre-sized silicate inclusions in E ring ice grains (Hsu et al., 2011) further support this finding. As with the gas phase, the presence of organic compounds is also conjectured for the icy solids (Hillier et al., 2007; Postberg et al., 2008), but their precise nature is currently unconstrained.

In the plume, salt-rich particles were found to be more abundant close to jet sources. Postberg et al. (2011) concluded that these must be larger grains, ejected at lower speeds. As a consequence, the overwhelming part of the dust mass ejected into the plume is saltrich whereas the small and fast salt-poor grains dominate (by number) the dust fraction that escapes into the $\mathrm{E}$ ring. A third type of dust particle was observed by Cassini's plasma instrument (Jones et al., 2009). To be detectable by this instrument, the grains must not be larger than a few nanometres, if singly charged. The locations where these small particles are detected are closely associated with the strongest jets in the plume. Precise determination of the different particle populations and their correlation with the jets is crucial to better understand the source of the jets and their interaction with the Saturnian environment.

\subsubsection{Plume interaction with the magnetosphere}

Enceladus is the main source of material in Saturn's magnetosphere, playing a similar role to Io in the Jovian system. On one 


\section{Enceladus: an active ice moon with aqueous processes}

a Bright jets emanating from Enceladus South Pole

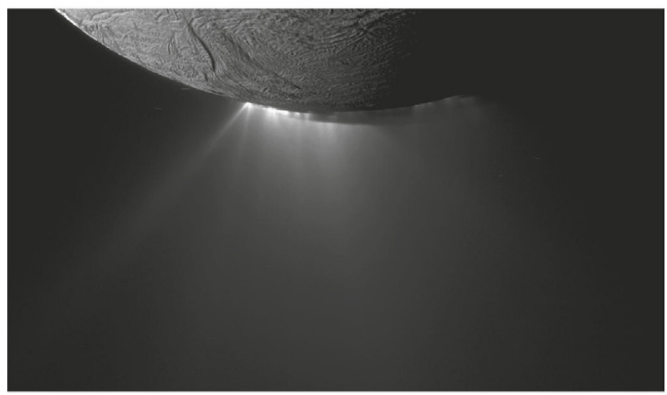

C Salt-rich ice grains detected near Enceladus

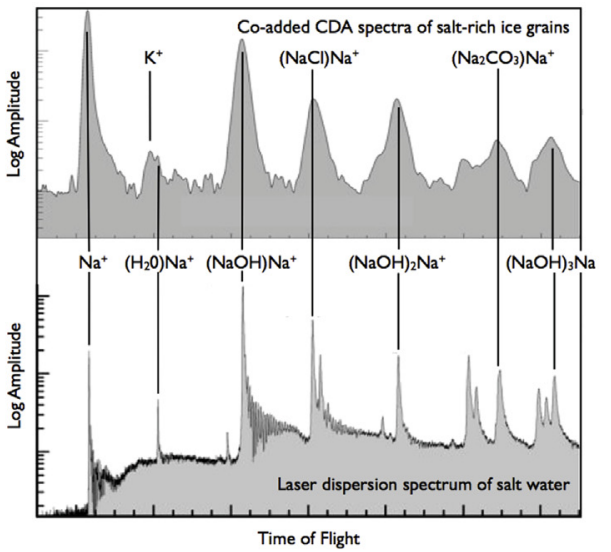

e variations of plume brightness along the orbit

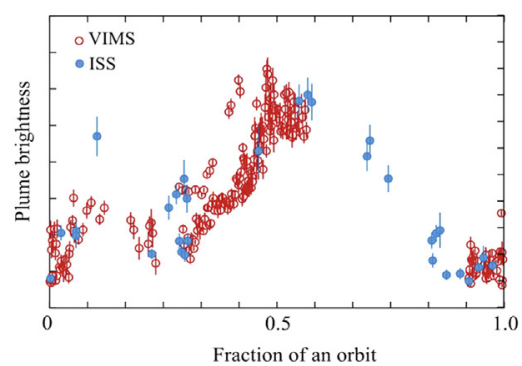

b Composition of Encealdus's vapour plume

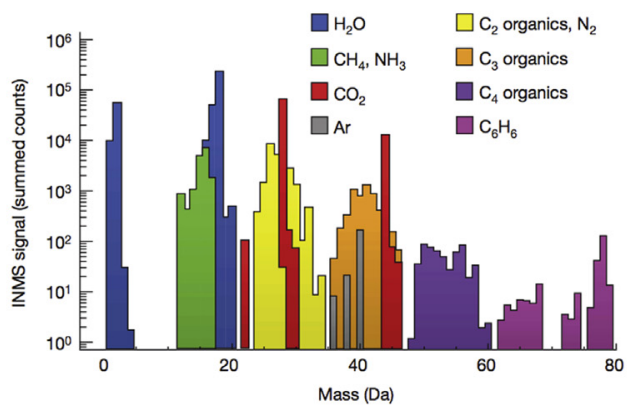

d

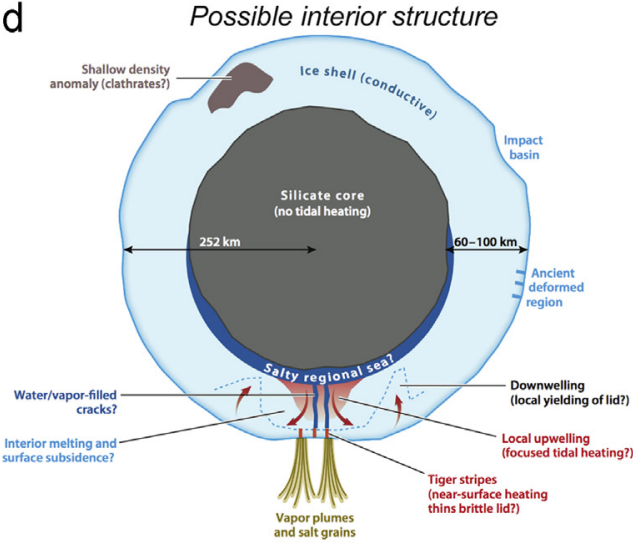

$f$

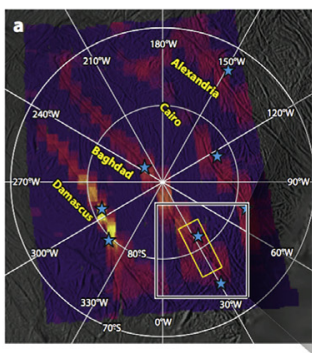

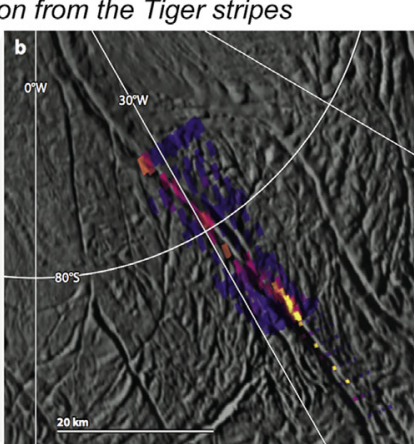

Fig. 4. (a) Cassini/ISS images showing eruption activity over the South Pole of Enceladus (Porco et al., 2014); (b) composition of Enceladus' vapor plume determined by the mass spectrometer INMS onboard Cassini (Waite et al., 2009); (c) comparison between co-added Cassini/CDA spectra of salt-rich water ice grains detected near Enceladus and a spectrum of laser-dispersed salty water provided proof for a subsurface water reservoir (Postberg et al., 2009, 2011); (d) diagram showing a possible interior structure of Enceladus (Spencer and Nimmo, 2013); (e) variation in brightness of Enceladus' plume, as a function of the moon's orbital position, observed by ISS (blue dots) (Nimmo et al., 2014) and VIMS (red dots) (Hedman et al., 2013) (credit: NASA/JPL-Caltech/Space Science Institute); (f) thermal emission at 10-17 $\mu \mathrm{m}$ from the tiger stripes as mapped by Cassini, superposed on a map based on visible-wavelength images (Spencer and Nimmo, 2013) (credit: NASA/JPL/GSFC/SwRI/Sapce Science Institute) (For interpretation of the references to color in this figure caption, the reader is referred to the web version of this paper.).

hand, the gas plume constitutes an obstacle for the corotational Kronian plasma. The deflected plasma forms a system of currents that lead to measurable deviations in the planetary dipolar magnetic field and the corotational electric field (Dougherty et al., 2006; Kriegel et al., 2009, 2011; Jia et al., 2010) and charge exchange collisions lead to an effective deceleration of the corotational plasma. On the other hand, the plume gas feeds a neutral torus around the orbit of Enceladus (Burger et al., 2007; Fleshman et al., 2010). Electron impacts and photoionization ionize neutrals in the plume and torus, thus replenishing the magnetospheric plasma (Tokar et al., 2006, 2008, 2009; Fleshman et al., 2010). The possible importance of dust-charging processes for the electromagnetic field close to the plume has been emphasized (Simon et al., 2011; Kriegel et al., 2011), and the presence of a dusty plasma was conjectured for the plume (Wahlund et al., 2009;
Shafiq et al., 2011). Such conclusions are subject to controversial debate and a future mission provides a unique opportunity to verify and quantify the related processes and settle these issues.

\subsubsection{Plume source and surface activity}

Qualitatively, a consistent picture based on the presence of liquid water on Enceladus seems to emerge. Only in this way can the elevated salinity of the dust particles be understood (Postberg et al., 2009, 2011). Salt-rich particles could form by direct dispersion from liquid, possibly when bubbles of exsolved gases burst at the liquid's surface (Matson et al., 2012). This scenario could also resolve the problem with the large dust/vapor ratio (Ingersoll and Ewald, 2011) and the observation of fairly large (and massive) particles in the lower parts of the plume (Hedman et al., 2009). 
Additional mass could condense on these particles when they are transported upwards in the supersaturated vents below the ice crust. In contrast, salt-poor (Postberg et al., 2009, 2011) and nanosized grains (Jones et al., 2009) might form by direct homogeneous condensation from the gas phase (Schmidt et al., 2008). Water vapor in the plume would then directly evaporate from liquid. Some non-water volatile compounds in the plume gas (Waite et al., 2006, 2009; Hansen et al., 2011) could be released at a quasisteady rate from the warm ice close to the liquid, or in depressurized zones close to the cracks.

Although recent observations by Cassini/VIMS and ISS indicate variability in the jet activity (Hedman et al., 2013; Nimmo et al., 2014), this activity is not yet fully characterized and the origin of the time variations are not fully understood. Stellar occultations from UVIS indicate little or no variability of the vapor production rate over a time-span of 5 years (Hansen et al., 2011), which appears in contradiction with the jet observations. Moreover, when viewed at different Enceladus' orbital true anomalies, the small observed changes appear to contradict the predictions of tidally driven eruption models (Hurford et al., 2012), while variability in plume brightness seen by VIMS seems consistent with such models (Hedman et al., 2013; Nimmo et al., 2014). Generally, limited spatial and temporal resolution of remote Cassini observations as well as the uncertain phase-function of the plume hamper the determination of possible variations with orbital true anomaly. Multiple, dedicated close flybys by a future spacecraft performed at different orbital true anomalies will permit an accurate determination of correlations between eruption activity and tidal cycles, as well as comparison with activity observed by Cassini.

\subsubsection{Evidence for subsurface salt-water reservoirs on Enceladus}

The detection of salt-rich ice grains in the plume (Postberg et al., 2011) clearly indicates the existence of a subsurface saltwater reservoir on Enceladus (Fig. 4). The presence of a liquid water reservoir is also supported by the gravity measurements performed by Cassini (less et al., 2014), as well as by models of tidal deformation (e.g. Nimmo et al., 2007; Tobie et al., 2008) (Fig. 4d). The low K/Na ratio in salt-bearing ice grains (Postberg et al., 2009) further indicates that water-rock interactions at the origin of the salt enrichment occurred at relatively low temperature (Zolotov, 2007; Zolotov et al., 2011). Such enrichment suggests efficient leaching processes and prolonged water-rock interactions. The involved chemical exchanges may be quantified by measuring accurately the ratio between radiogenic and nonradiogenic isotopes in noble gases ( $\mathrm{Ar}, \mathrm{Ne}, \mathrm{Kr}, \mathrm{Xe}$ ) in Enceladus' plume and by determining more precisely the composition of organics, salts, and other minerals contained in sampled ice grains. The size and composition of the internal ocean - if any - must also be addressed. Monitoring tides and rotation (via measurements of altimetry, gravity, surface tracking) as well as magnetic signals may provide essential information on the ocean extent, density and electric conductivity, thus constraining its composition.

\subsubsection{Geodynamical evolution of Enceladus}

Enceladus' icy surface reveals a wide variety of tectonic structures that record a long history of tectonic deformation (Spencer et al., 2009). Ancient tectonically modified plains identified outside the active south-polar region (Crow-Willard and Pappalardo, 2010) suggest a complex geological history with multiple episodes of enhanced activity. Long-wavelength topography, as well as heterogeneity in crater distribution and tectonic activity, probably reflect strong temporal and spatial variations in ice shell thermal structure (Schenk and McKinnon, 2009; Kirchoff and Schenk, 2009). As indicated by the huge heat flow emitted from the Tiger stripes
(Spencer and Nimmo, 2013, Fig. 4f), tidal interaction dominates the moon's evolution. Variations of endogenic activity are expected due to coupling with the orbital evolution. However, it is still unknown how activity varies on geological timescales. Surface and sub-surface mapping of Enceladus will permit a better understanding of its long-term evolution.

\section{Science goal C: chemistry of Titan and Enceladus - clues for the origin of life}

Both Titan and Enceladus possess several, if not all, of the key components for habitability: internal liquid water, organic material, energy sources, and a stable environment. Complex organics discovered in Titan's upper atmosphere indicate that a very rich organic chemistry is occurring on Titan (Fig. 3a and b). How these organic compounds formed, and how they evolve once at the surface and buried in the subsurface remain open questions. Organic compounds are also strongly indicated in Enceladus' plume, though not precisely identified. The presence of salt water as a plume source further increases the astrobiological potential of Enceladus. Titan and Enceladus offer an opportunity to study analogous prebiotic processes that may have led to the emergence of life on Earth. Goal C seeks to determine the degree of chemical complexity on the two moons, to analyse chemical processes that may have prebiotic implications.

\subsection{Similarities of Titan and Enceladus with the early earth}

Retracing the processes that allowed the emergence of life on Earth around $4 \mathrm{Ga}$ ago is a difficult challenge since most traces of the environmental conditions at that time have been erased. It is, therefore, crucial for astrobiologists to find extraterrestrial planetary bodies with similarities to our planet, providing a way to study some of the processes that occurred on the primitive Earth, when prebiotic chemistry was active. Although Titan is much colder than the Earth, and has formed in a different environment, it nevertheless presents - perhaps more than any other object in the Solar System - striking analogies with our planet. A major example is Titan's atmosphere, which is composed of the same main constituent, nitrogen, and has a similar structure with a surface pressure of 1.5 bar. Methane's complex cycle on Titan mimics that of water on the Earth and generates, with nitrogen, a large inventory of organic molecules leading to an intense prebiotic chemistry, such as hydrogen cyanide (HCN) and cyanoacetylene $\left(\mathrm{HC}_{3} \mathrm{~N}\right)$ (Raulin et al., 2012). Moreover, Titan is the only planetary body, other than the Earth with long-standing bodies of liquid on its surface, albeit hydrocarbons instead of water. The degree of complexity that can be reached from organic chemistry in the absence of permanent liquid water bodies on Titan's surface, however, has yet to be determined.

Analogies also concern potential habitats. Although quite speculative, Titan lakes could harbor very exotic life (McKay and Smith, 2005; Schulze-Makuch and Grinspoon, 2005), using energy provided by the reduction of hydrocarbons into methane, cell membranes made of reversed vesicles (Norman and Fortes, 2011) and no liquid water. Another place is the likely internal liquid water reservoir mixed with some ammonia. Models of Titan's formation even suggest that, initially, this subsurface ocean was in direct contact with the atmosphere and with the internal bedrock (e.g. Tobie et al., 2006; Lunine et al., 2009), offering interesting analogies with the primitive Earth, and the potential implication of hydrothermal vents in terrestrial-like prebiotic chemistry. It cannot be excluded that life may have emerged in this environment and may have been able to adapt and persist since the current conditions are not incompatible with life as we know it on Earth (Fortes, 2000). Thus, it seems essential to confirm the presence 
of this ocean and determine some of its properties. With the likely presence of subsurface salt-water reservoirs, Enceladus also offers interesting analogies with terrestrial oceans and subglacial lakes. The co-existence of organic compounds, salts, liquid water and energy sources on this small moon provides all necessary ingredients for the emergence of life by chemoautotrophic pathways (McKay et al., 2008) - a generally held model for the origin of life on Earth in deep sea vents. In this model, life on Earth began in deep sea hot springs where chemical energy was available from a mix of $\mathrm{H}, \mathrm{S}$, and $\mathrm{Fe}$ compounds. The fact that the branches of the tree of life that are closest to the common ancestor are thermophilic has been used to argue a thermophilic origin of life - although other explanations are possible. In situ sampling of the plume provides a unique opportunity to search for the specific molecules associated with such systems, including $\mathrm{H}_{2}, \mathrm{H}_{2} \mathrm{~S}$, $\mathrm{FeS}$, etc., and to study processes analogous to those involved with the origin of life on Earth.

\subsection{Origin and evolution of volatile compounds on Titan and Enceladus}

A preliminary requirement for assessment of the astrobiological potential of Titan and Enceladus is to constrain the origin(s) of volatile compounds and to determine how their inventory evolved since satellite accretion. The present-day composition of Titan's atmosphere, as revealed by Cassini-Huygens, results from a combination of complex processes including internal outgassing, photochemistry, escape and surface interactions. The detection of a significant amount of ${ }^{40} \mathrm{Ar}$ (the decay product of ${ }^{40} \mathrm{~K}$ ) by CassiniHuygens (Niemann et al., 2005, 2010; Waite et al., 2005) indicated that a few per cent of the initial inventory was outgassed from the interior. The chemical exchanges with the surface and the interior as well as the initial composition, however, still remain unconstrained (e.g. Tobie et al., 2014). In contrast, the analysis of Enceladus' plumes provides a unique opportunity to observe eruptive processes in real time and to constrain the composition of the building blocks of the Saturnian system (Waite et al., 2009). Comparison between Titan and Enceladus thus enables us to differentiate what was inherited during formation from what was acquired during their evolution.

The isotopic ratios in different gas compounds observed on Titan and Enceladus constitute crucial constraints to assess their origin and evolution. Cassini-Huygens and ground-based measurements provided isotopic ratios of $\mathrm{H}, \mathrm{C}, \mathrm{N}$, and $\mathrm{O}$ in $\mathrm{N}_{2}, \mathrm{CO}, \mathrm{CH}_{4}$, HCN and $\mathrm{C}_{2}$ hydrocarbons at various altitudes in Titan's atmosphere (e.g. Mandt et al., 2012; Nixon et al., 2012). The measured ${ }^{15} \mathrm{~N} /{ }^{14} \mathrm{~N}$ ratio is enigmatic because it is about $60 \%$ higher than the terrestrial value (Niemann et al., 2010), suggesting an abnormally high fractionation. In contrast, ${ }^{13} \mathrm{C} /{ }^{12} \mathrm{C}$ in methane implies little to no fractionation, suggesting that methane has been present in the atmosphere for less than a billion years (Mandt et al., 2012). In the absence of a proper initial reference value, however, it is impossible to retrieve information on fractionation processes with confidence. Precise isotopic ratios in the photochemical by-products of $\mathrm{CH}_{4}$ and $\mathrm{N}_{2}$ on Titan are also lacking. Except for $\mathrm{D} / \mathrm{H}$ in $\mathrm{H}_{2} \mathrm{O}$ on Enceladus (with large error bars Waite et al., 2009), no information is yet available for the isotopic ratio in Enceladus' plume gas. Simultaneous precise determination of isotopic ratios in $\mathrm{N}, \mathrm{H}, \mathrm{C}$ and $\mathrm{O}-$ bearing species in Enceladus' plume and Titan's atmosphere will permit a better determination of the initial reference ratio and a quantification of the fractionation process due to atmospheric escape and photochemistry.

In situ sampling of the plasma and energetic particle environment surrounding Titan is also required to provide a better understanding of present escape. Saturn's magnetospheric plasma consists of primarily of water group ions $\left(\mathrm{O}^{+}, \mathrm{OH}^{+}, \mathrm{H}_{2} \mathrm{O}^{+}\right), \mathrm{H}_{2}^{+}$, protons, and electrons near Titan (Thomsen et al., 2010). These ions impact Titan's thermosphere primarily heating the thermosphere, but also ionizing the local gas (Westlake et al., 2011; Shah et al., 2009; Smith et al., 2009). The oxygen and water group ions in the $1-100 \mathrm{keV}$ range are most efficient at heating the thermosphere (Shah et al., 2009), while protons deposit their energy below the homopause (Smith et al., 2009). Energetic electrons (up to a few $\mathrm{keV}$ ) impact the thermosphere primarily near $1200 \mathrm{~km}$. There are two complimentary methods for determining the energy input into Titan's upper atmosphere, both of which were flown on Cassini: in situ measurements of upstream ions with energy and composition determination, and remote sensing of the atmospheric interaction through energetic neutral atom (ENA) detection. In situ measurement upstream and near Titan will identify the composition and energetics of Saturn's magnetospheric flow near Titan, with a sufficient fidelity magnetic field model derived from measurements the particles can be propagated into the thermosphere to determine the energy deposition. Remote ENA observations give the global energy deposition in Titan's thermosphere, and can also sense the structure and the extent of the exosphere (Brandt et al., 2012).

\subsection{Titan complex prebiotic-like chemistry}

In Titan's atmosphere, the coupling between $\mathrm{CH}_{4}$ and $\mathrm{N}_{2}$ chemistries produces many organics in the gas and particulate phases, especially hydrocarbons, nitriles and complex refractory organics (Fig. 3d). The latter seem to be well modeled by the solid products, commonly called the "tholins", formed in laboratory simulation (e.g. Cable et al., 2012). Water and oxygen ions coming from a magnetospheric source linked to Enceladus plumes are also involved in this atmospheric chemistry (e.g. Sittler et al., 2009). Could these water-oxygen compounds then be locked up into aerosols? Several organic compounds have already been detected in Titan's stratosphere, including hydrocarbons and nitriles (Coustenis et al., 2007, 2010; Teanby et al., 2009a, Fig. 3c). Direct analysis of the ionosphere by the INMS instrument during the closest Cassini flybys of Titan shows the presence of many organic species at very high altitudes (1100-1300 km): the INMS and CAPS measurements strongly suggest that high-molecular-weight species (up to several $1000 \mathrm{u}$.) are present in the ionosphere (Waite et al., 2007, Fig. 3a and b). This unexpected discovery revolutionizes the understanding of the organic processes occurring in Titan's atmosphere, indicating that ionospheric chemistry plays a key role in the formation of complex organic compounds in Titan's environment. It is essential to determine ionosphere ion and neutral composition with sufficient mass range and resolution to study a wide range of organically relevant compounds. A mass range extending from 10 to about $10,000 \mathrm{u}$., with a mass resolution $(\mathrm{m} / \delta \mathrm{m})$ of at least 10,000 , is necessary to determine with no ambiguity the elemental composition (in $\mathrm{C}, \mathrm{H}, \mathrm{O}$ and $\mathrm{N}$ ) for a wide range of organic compounds. Isotopic knowledge for these compounds would require even greater mass resolution, generally 30,000 .

The presence of water vapor and benzene has been unambiguously confirmed by the CIRS instrument, which also detected isotopomers of several organics (Nixon et al., 2008; Coustenis et al., 2010). The GCMS data collected during the descent of the Huygens probe show that the middle and lower stratosphere and the troposphere are poor in volatile organic species, with the exception of methane (Niemann et al., 2005, 2010). Condensation of such species on aerosol particles is a probable explanation for these atmospheric characteristics. The Huygens ACP instrument carried out the first in situ chemical analysis of these particles. The results show that they are made of nitrogen-rich refractory organics, which release $\mathrm{HCN}$ and $\mathrm{NH}_{3}$ during pyrolysis, supporting the tholin hypothesis (Israël et al., 2005; Coll et al., 2013). These measurements suggest that the aerosol 
particles are made of a refractory organic nucleus, covered with condensed volatile compounds. However, neither the nature and abundances of the condensates nor the elemental composition and the molecular structure of the refractory part of the aerosols have been determined. Moreover, the chirality of its complex organic part is unknown.

The nitrogen content of the aerosols means they are of immediate astrobiological interest following their production in the upper atmosphere (Hörst et al., 2012). Once deposited on Titan's surface, aerosols and their complex organic content produced by atmospheric chemistry may also follow a chemical evolution of astrobiological interest. Laboratory experiments show that, once in contact with liquid water, tholins can release many compounds of biological importance, such as amino acids and purines (Poch et al., 2012). Such processes could be particularly favorable if liquid water is brought to the surface by cryovolcanism (Lopes et al., 2007) or cratering events (Artemieva and Lunine, 2003). Thus one can envision the possible presence of such compounds on Titan's surface or near subsurface. Long-term chemical evolution is impossible to mimic experimentally in the laboratory. It is, therefore, crucial to be able to perform a detailed chemical analysis (at the elemental, molecular, isotopic and chiral levels) of the various types of surface zones, particularly those where cryovolcanism and impact ejecta (or melt sheets) are or have been present.

\subsection{Enceladus' prebiotic aqueous processes}

The jets emanating from Enceladus' south pole are probably the most accessible samples from an extra-terrestrial liquid water environment in the Solar System. In addition to water ice, jets include $\mathrm{CO}_{2}$ and several organics such as methane, propane, acetylene, and even higher molecular weight compounds with masses exceeding $100 \mathrm{u}$., present in the gas and ice grains (Waite et al., 2009). Most of the erupted ice grains contain significant amounts of sodium and potassium salts (about 1\%) indicating that salt water plays an important part as a plume source (Postberg et al., 2009, 2011), which suggests contact with Enceladus' rocky core. The ice grains also carry tiny silicate particles that may have previously floated in the liquid (Hsu et al., 2011). The total heat emission at the south polar Tiger Stripes is at least 5 GW (possibly up to $15 \mathrm{GW}$, Howett et al., 2011), and in some of the hot spots where jets emanate, the surface temperatures are estimated to exceed $200 \mathrm{~K}$ (Spencer et al., 2011). Such enormous heat output, associated with liquid water in contact with rocks, favors prebiotic processes, providing both an energy source and mineral surfaces for catalyzing chemical reactions.

The low molecular weight organics detected by Cassini may be just one part of a suite of organics present in the plume and on the surface. Studies of the nature of these organics could tell us whether or not they are biogenic. The molecular species likely to be produced by such a prebiotic or biotic chemistry such as amino acids, heterocyclic bases, lipidic compounds and sugars - could be detected in the plume of Enceladus using in situ techniques. It is also crucial to confirm the presence of liquid water reservoirs and to constrain their composition, both by remote sensing and in situ measurements.

\subsection{Summary of science questions, investigations and key measurements relevant for Goals $A, B$ and $C$}

Tables 1-3 summarize the different key questions and the corresponding investigations that should be addressed by a future Large-class mission for the three main science goals. The measurements, both from orbit and in situ from a balloon, required to address these scientific objectives are listed in Tables 4-6. Further details on the mission concepts and relevant instruments are provided in Section 7.

\section{Mission concept}

\subsection{Previous mission concepts for post-Cassini-Huygens exploration of Titan and Enceladus}

Future exploration of the Saturnian system with a focus on Titan and Enceladus has been considered for quite some time, almost since the first years of the Cassini-Huygens mission. Early discoveries by Cassini-Huygens at Titan and Enceladus (discussed

Table 1

Summary of science questions, investigations and key measurements relevant for Goal A.

\begin{tabular}{|c|c|c|}
\hline A: Titan as an Earth-like system & Saturn-Titan Orbiter & Titan Balloon \\
\hline How does Titan's methane cycle vary with season? & Cloud distribution, lake changes [A-1, A-2] & $\begin{array}{l}\text { Rain, surface evaporation, detailed cloud } \\
\text { activity }[\mathrm{A}-12, \mathrm{~A}-13]\end{array}$ \\
\hline How does Titan's global circulation vary with season? & Cloud tracking, Doppler and thermal winds [A-2, A-3] & $\begin{array}{l}\text { Balloon tracking, tropospheric winds } \\
\text { [A-14] }\end{array}$ \\
\hline $\begin{array}{l}\text { What is Titan's atmospheric temperature structure and how does } \\
\text { this influence atmospheric escape, photochemistry, and haze } \\
\text { production? }\end{array}$ & $\begin{array}{l}\text { In situ upper atmosphere, remote sensing, } \\
\text { occultations }[A-3, A-4, A-5]\end{array}$ & $\begin{array}{l}\text { Tropospheric temperatures, condensation } \\
\text { processes }[\mathrm{A}-12]\end{array}$ \\
\hline $\begin{array}{l}\text { How are hazes distributed globally and seasonally? What causes the } \\
\text { detached haze layer? }\end{array}$ & $\begin{array}{l}\text { Imaging, spectroscopy, middle atmosphere } \\
\text { distribution/composition }[A-2, A-4]\end{array}$ & $\begin{array}{l}\text { Tropospheric hazes distribution and } \\
\text { composition }[\mathrm{A}-13]\end{array}$ \\
\hline $\begin{array}{l}\text { What is the composition of Titan's atmosphere? How does it change } \\
\text { over seasonal timescales? }\end{array}$ & $\begin{array}{l}\text { Global spectroscopy, in situ upper atmosphere [A-3, } \\
\text { A-4] }\end{array}$ & $\begin{array}{l}\text { High precision in situ gas and isotopes } \\
\text { [A-12] }\end{array}$ \\
\hline $\begin{array}{l}\text { How old is Titan's surface? What erosional processes are currently } \\
\text { active on Titan? }\end{array}$ & $\begin{array}{l}\text { High resolution imaging of craters, aeolian, fluvial } \\
\text { and glacial features, surface changes [A-6, A-7, A-8, } \\
\text { A-9] }\end{array}$ & $\begin{array}{l}\text { Very high resolution surface imaging: } \\
\text { morphology and activity [A-15, A-16, A-17, } \\
\text { A-18] }\end{array}$ \\
\hline $\begin{array}{l}\text { What are the properties of Titan's lakes (composition, waves)? How } \\
\text { do they vary over seasonal and geological timescales? }\end{array}$ & $\begin{array}{l}\text { Distribution, seasonal change, lake depths [A-1, A-8, } \\
\text { A-9] }\end{array}$ & $\begin{array}{l}\text { Shoreline imaging, lake clouds, dry } \\
\text { lakebeds [A-15, A-16, A-17] }\end{array}$ \\
\hline $\begin{array}{l}\text { What is the composition of Titan's surface and how does it interact } \\
\text { with the atmosphere and subsurface? }\end{array}$ & $\begin{array}{l}\text { High-resolution global spectroscopy, hydrocarbon } \\
\text { deposits }[\text { A-6, A-7, A-9] }\end{array}$ & $\begin{array}{l}\text { Very high spatial resolution spectroscopy, } \\
\text { deposits }[A-16, A-17]\end{array}$ \\
\hline $\begin{array}{l}\text { Are cryovolcanic and tectonic processes currently active on Titan? } \\
\text { Have these endogenic processes been active in the past? }\end{array}$ & $\begin{array}{l}\text { Cryovolcanic and tectonic features [A-6, A-7, A-8, } \\
\text { A-9] }\end{array}$ & $\begin{array}{l}\text { Very high spatial resolution imaging: } \\
\text { morphology, activity [A-15, A-16, A-17, } \\
\text { A-18] }\end{array}$ \\
\hline $\begin{array}{l}\text { What is the origin of Titan's atmosphere? How has it evolved since } \\
\text { its formation? What is the resupply process of methane? }\end{array}$ & Isotopic ratio, noble gas, atmospheric escape [A-4] & Isotopic ratios, noble gases [A-1, A-18] \\
\hline $\begin{array}{l}\text { What is Titan's internal structure? What are the properties of any } \\
\text { internal ocean and of the icy shell? }\end{array}$ & $\begin{array}{l}\text { Gravity, topography, spin state, magnetic field [A-10, } \\
\text { A-11] }\end{array}$ & Electric field [A-19] \\
\hline
\end{tabular}


Table 2

Summary of science questions, investigations and key measurements relevant for Goal B.

\begin{tabular}{|c|c|c|}
\hline B: Enceladus as an active cryovolcanic moon & Saturn-Titan Orbiter & $\begin{array}{l}\text { Titan } \\
\text { Balloon }\end{array}$ \\
\hline $\begin{array}{l}\text { What is the composition of Enceladus' plume and what implications does this have for origin } \\
\text { of the Saturn system icy moons? }\end{array}$ & $\begin{array}{l}\text { In situ gas and ice grain sampling, occultations: organic } \\
\text { compounds, noble gases, isotopic ratios [B-1, B-2, B-3] }\end{array}$ & - \\
\hline What are the characteristics of the plume source region and origin of the plume salts? & $\begin{array}{l}\text { Thermal/visible imaging, in situ ice grain sampling, subsurface } \\
\text { sounding, time variability [B-2, B-3, B-9, B-10] }\end{array}$ & - \\
\hline $\begin{array}{l}\text { What dust-plasma interactions occur within the plume? How does the plume interact with } \\
\text { Saturn's magnetosphere? }\end{array}$ & $\begin{array}{l}\text { In situ sampling, occultation, magnetic field, plasma [B-1, B-2, } \\
\text { B-3, B-13] }\end{array}$ & - \\
\hline $\begin{array}{l}\text { What processes drive the surface and plume activities and is this a long-lived or transient } \\
\text { phenomenon? }\end{array}$ & $\begin{array}{l}\text { Heat flow, tectonic morphology and distribution, change in } \\
\text { plume activity [B-4, B-5, B-6, B-7, B-8, B-9, B-10] }\end{array}$ & - \\
\hline $\begin{array}{l}\text { What are the internal structure and properties of any internal ocean? How is this coupled to } \\
\text { the ice shell and the rocky core? }\end{array}$ & $\begin{array}{l}\text { Gravity, topography, spin state, magnetic field, orbital } \\
\text { dynamics [B-11, B-12, B-13] }\end{array}$ & - \\
\hline
\end{tabular}

Table 3

Summary of science questions, investigations and key measurements relevant for Goal C.

\begin{tabular}{|c|c|c|}
\hline C: Chemistry of Titan and Enceladus - clues to the origin of life & Saturn-Titan Orbiter & Titan Balloon \\
\hline $\begin{array}{l}\text { What are the compositions of the heavy ions and neutrals found in } \\
\text { Titan's upper atmosphere? }\end{array}$ & In situ mass spectrometry [C-1] & - \\
\hline $\begin{array}{l}\text { What is the composition of Titan's haze? Are there variations in } \\
\text { composition with altitude, latitude and/or season? }\end{array}$ & $\begin{array}{l}\text { Spectroscopy/in situ of haze forming } \\
\text { and intermediate regions [C-2] }\end{array}$ & In situ analysis of aerosols in the troposphere [C-10] \\
\hline $\begin{array}{l}\text { How do organic compounds evolve on Titan's surface? Do these } \\
\text { compounds interact with liquid water in cryovolcanic or impact } \\
\text { sites? }\end{array}$ & $\begin{array}{l}\text { Global spectroscopy, subsurface } \\
\text { sounding }[C-3, C-4, C-5]\end{array}$ & $\begin{array}{l}\text { Very high spatial resolution spectral imaging, surface } \\
\text { sampling, subsurface sounding [C-11, C-12, C-13, } \\
\text { C-14] }\end{array}$ \\
\hline $\begin{array}{l}\text { What is the nature of Enceladus' chemistry? Does the plume contain } \\
\text { complex molecules of astrobiological interest? }\end{array}$ & $\begin{array}{l}\text { in situ gas and grain sampling, surface } \\
\text { mapping }[C-6, C-7, C-8]\end{array}$ & - \\
\hline $\begin{array}{l}\text { Do water reservoirs exist at shallow depths on Enceladus? How does/ } \\
\text { did liquid water interact with rocky and/or organic material on } \\
\text { Enceladus? }\end{array}$ & $\begin{array}{l}\text { Surface spectral-mapping, geophysics, } \\
\text { in situ gas and grain sampling [C-6, C-9] }\end{array}$ & - \\
\hline
\end{tabular}

Table 4

Measurement requirements to address the science questions of Goal A.

Goal A: Titan as an Earth-like system

\section{Saturn-Titan Orbiter}

A-1. Detect seasonally driven surface changes in the methane hydrological cycle, in particular lakeextent

A-2. Map the formation and dissipation of clouds, and determine their altitude.

A-3. Determine temperature, wind fields and the abundances of the gaseous + solid constituents in the A-14. Determine wind directions in the troposphere and the

stratosphere and agnostosphere (500-950 km) versus altitude and latitude, with a goal of detecting interaction with the surface in dune fields seasonally driven changes.

A-4. Collect molecular species (ion and neutral) from one pole to the equator, with an altitude goal of $600 \mathrm{~km}$ for in situ orbiter measurements at certain points, covering lower altitudes with remote techniques

A-5. Determine exchange of energy and escape of major volatile species, including $\mathrm{H}_{2}$, methane and $\mathrm{N}_{2}$, by comprehensive longitudinal sampling

A-6. Map at least $80 \%$ of the surface to $50 \mathrm{~m}$ resolution, in one near-infrared band

A-7. Map the spatial distribution of simple hydrocarbons and important geologic materials

A-8. Determine the topography by altimetry over $80 \%$ of the surface with $10 \mathrm{~m}$ vertical resolution

A-9. Perform the sub-surface sounding (lakes, dunes, crustal layering) with $10-\mathrm{m}$ vertical resolution

A-10. Determine Titan's gravity field, and its time-variation, with an accuracy of $10^{-9} \mathrm{~m} \mathrm{~s}^{-2}$ at an

altitude of $1500 \mathrm{~km}$, and to degree and order 6

A-11. Characterize magnetic induction and magnetospheric interactions

\section{Titan Balloon}

A-12. Determine profiles of $\mathrm{T}, \mathrm{P}, \mathrm{CH}_{4}, \mathrm{C}_{2} \mathrm{H}_{6}$ and other organic molecule mole fraction

A-13. Track cloud motions and determine particle size and properties of clouds and haze
A-15. Acquire regional geological maps at $2.5 \mathrm{~m}$ resolution and measure regional topography.
A-17. Perform subsurface sounding (with vertical resolution $<10 \mathrm{~m}$ )
A-18. Search for methane source and possible cryovolcanic activity

A-19. Determine electric and magnetic perturbations above) demonstrated the need for further exploration of the two satellites with a dedicated orbiter, and a balloon for in situ exploration of Titan, with advanced instrumentation specifically adapted for the environments revealed by Cassini-Huygens, and possibly at different seasonal periods. To place our proposed mission concept in this context, previously proposed mission concepts are briefly outlined below.

The Titan explorer (Lorenz et al., 2008a) and the Titan and Enceladus Mission (TandEM Coustenis et al., 2009) concepts had been selected respectively by NASA and ESA for studies before they were merged into the joint large (Flagship) Titan and Saturn System Mission (TSSM) concept, which was extensively studied in 2008 (TSSM report, Reh et al., 2008a,b). TSSM aimed at an in-depth longterm exploration of Titan's atmospheric and surface environment and in situ measurements in one of the Titan's lakes with goals to explore Titan as an Earth-like System, to examine Titan's organic inventory and to explore Enceladus and the coupling and interaction of the two moons with Saturn's magnetosphere. To achieve these goals, a 
Table 5

Measurement requirements to address the science questions of Goal B.

B: Enceladus as an active cryovolcanic moon

Saturn-Titan Orbiter

B-1. Determine the spatial distribution, and possible time variations, of gas compounds in the plume, from in situ sampling and occultation, with at least $\mathrm{M} / \Delta \mathrm{M} \sim 10,000$ and a detection limit at least 1000-x lower than Cassini

B-2. Determine density, as well as velocity and size distribution of the ice grains and their spatial and temporal variations with at least 0.5 km spatial resolution

B-3. Determine the mass spectra of ice grains from $1 \mathrm{u}$. to $500 \mathrm{u}$. with at least 10 -x higher mass resolution and 100 -x better spatial resolution than Cassini B-4. Map surface features at global scale with at least $0.5 \mathrm{~km}$ spatial resolution.

B-5. Map surface composition (water ice, frost, non-water compounds) at $1 \mathrm{~km}$ spatial resolution at global scale, and down to $300 \mathrm{~m}$ spatial resolution on regional scales

B-6. Map surface features at $1 \mathrm{~m}$ spatial resolution for selected candidate locations, in particular around the identified jet sources

B-7. Acquire regional topography maps of Enceladus' surface with a spatial resolution up to $0.1 \mathrm{~km}$ and a vertical resolution of $\sim 10 \mathrm{~m}$

B-8. Map the surface temperature distribution in active regions with a precision of $1 \mathrm{~K}$ and a spatial resolution of $100 \mathrm{~m}$

B-9. Sound the subsurface up to $5 \mathrm{~km}$ in depth, at $10 \mathrm{~m}$ vertical resolution over the active south pole region

B-10. Monitor possible time variations in activity of the jet sources

B-11. Determine degree-two gravity field and harmonic amplitudes at precisions of 10-7 of Enceladus' surface gravity

B-12. Monitor time variations of the gravity field, spin state and magnetic field

B-13. Measure global plasma and magnetic field structure in the vicinity of Enceladus

Table 6

Measurement requirements to address the science questions of Goal C.

C: Chemistry of Titan and Enceladus - clues to the origin of life

Saturn-Titan Orbiter $\quad$ Titan Balloon

C-1. Perform chemical analysis of the ions and neutral, including heavy species (up to several $1000 \mathrm{u}$.) in Titan's upper atmosphere

C-2. Perform chemical analysis of the haze particles in Titan's upper atmosphere: search for variations with latitude, altitude and time

C-10. Perform chemical analysis of the haze particles throughout the descent, and determine spatial and temporal variations in the troposphere

$\mathrm{C}-3$. Determine the isotopic composition in major $\mathrm{C}, \mathrm{H}, \mathrm{N}, \mathrm{O}$-bearing species in Titan's atmosphere and Enceladus' plume

C-4. Quantify the different isotopes of noble gases ( $\mathrm{Ar}, \mathrm{Ne}, \mathrm{Kr}, \mathrm{Xe}$ ) in Titan's atmosphere and Enceladus' plume

C-5. Determine the infrared spectra of Titan's surface: search for organics of astrobiological interest, and potential correlation with cryovolcanism or impact sites

C-6. Determine the nature of organics and salts contained in the icy grains of Enceladus' plume

C-7. Search for organics of astrobiological interest in the plume and on the surface near the jet sources

C-8. Perform chiral analysis of organic compounds and search for potential enantiomeric excess

C-9. Search for near-surface water reservoir on Enceladus

dedicated orbiter would have carried two in situ elements: the Titan montgolfière (hot air balloon) and the Titan Lake Lander, each of which would provide complementary data and analyses directly in the atmosphere and on the surface of Titan, and sound its interior. During the Saturn Tour phase, multiple flybys of Enceladus (and possibly of other moons) in addition to Titan would have been performed. The mission would have been launched in the 20232025 timeframe on a trajectory using Solar Electric Propulsion (SEP), as well as gravity assists, to arrive $\sim 9$ years later for a 4 -year mission in the Saturn system. Soon after arrival at Saturn, the montgolfière and Lake Lander would have been delivered to Titan. The three TSSM elements would have operated as follows:

- The orbiter, powered by MMRTGs (Multi-Mission Radioisotope Thermal Generators), would have performed seven close-up Enceladus flybys and then enter into orbit around Titan for 2 years of dedicated observations.

- The montgolfière would have studied both Titan's atmosphere and surface from above the equator at low altitude ( $\sim 10 \mathrm{~km})$ for at least 6 months using MMRTGs.
The Lake Lander would have performed the first extraterrestrial - oceanographic experiment by landing in one of the Titan's seas, the Kraken Mare, located at approximately $75^{\circ} \mathrm{N}$.

This mission was ranked second in the final decision by the agencies and was not considered for further study. It has, however, inspired several other proposed concepts for smaller size missions:

- Titan Aerial Explorer (TAE) was an M3 candidate for ESA's Cosmic Vision call (Lunine et al., 2011). TAE was a pressurized balloon, which was planned to fly in the lower atmosphere of Titan at an altitude of $8 \mathrm{~km}$ for 3-6 months over Titan's equatorial latitudes, with direct to Earth transmission and no need for an orbiter to relay data.

- The Aerial Vehicle for in situ and Airborne Titan Reconnaissance (AVIATR) was an alternative idea to the Titan balloon. In Titan's low gravity and a dense atmosphere, an ASRG (Advanced Stirling Radioisotope Generator) powered airplane could fly more easily than on Earth and could sample directly 
the atmosphere over large swaths of Titan's surface (Barnes et al., 2012).

- The Titan Mare Explorer (TiME), a Discovery candidate, was a probe focusing on exploring Titan's lakes by landing in and floating across Ligeia mare. This lander was designed to study the chemical composition, wave and geological characteristics of the lakes (Stofan et al., 2010). A similar idea was the Titan Lake Probe, which included a submarine concept (Waite et al., 2010).

- The Journey to Enceladus and Titan (JET) was a Discovery candidate Saturn orbiter with only two instruments and radio science that would explore the plume of Enceladus and the atmosphere and surface of Titan (Sotin et al., 2011).

\subsection{Mission concept involving a Saturn-Titan-Orbiter and a Titan-} Balloon for the exploration of Titan and Enceladus

The mission concept described below was proposed in response to the ESA call for the definition of the science themes of the next L-class mission (L2/L3), after the L1 JUICE mission. This mission concept is inspired from the ambitious TSSM concept, which included three elements (one orbiter and two in situ elements as mentioned above). We describe here a mission concept involving only two elements (Saturn-Titan Orbiter and Titan Balloon, Fig. 5). Note that a mission concept involving an orbiter and a lake probe is described in a companion paper by Mitri et al., 2014).

\subsubsection{Mission scenario and elements}

For the L2 and L3 launch opportunities, the duration of the cruise from Earth to Saturn were estimated at 8-10 years. Following the mission scenario of TSSM, on arrival at Saturn, the Saturn-Titan orbiter would deliver the Titan balloon, perform a Saturn Tour Phase of about 2 years with multiple flybys of Titan and Enceladus (and possibly of other moons), and finally be captured around Titan at the end of the Saturn Tour Phase in an elliptical orbit ( $700 \mathrm{~km}$ periapsis to $15,000 \mathrm{~km}$ apoapsis) followed by a 2-month aero-breaking phase. This aero-breaking phase would enable the exploration of a poorly known, but chemically critical, part of the atmosphere (700-800 km), with in situ atmospheric sampling at altitudes much lower than possible with Cassini. Following the aero-breaking phase, the orbiter would be placed into a circular $1500 \mathrm{~km}$, near-polar orbit, for the orbital science phase. This orbit allows detailed mapping of all latitudes with high temporal resolutions. The resulting complete global coverage would provide a substantial increase in our understanding of Titan's climatic system and allow global access to all types of surface terrain, atmospheric phenomena, and upper atmosphere interactions.

The Saturn Tour Phase would be optimized for Enceladus science via numerous flybys targeted over Enceladus' southern plumes and geological features, or potentially other ancient active regions elsewhere on the moon. Additionally, the Saturn Tour Phase would allow direct in situ study of the possible transport of (organic) material between Enceladus and Titan, and indirectly to other parts of the Saturnian system.

The Titan balloon would be deployed during the first Titan flyby. Data would be transmitted to the orbiter via a steerable high gain antenna, for relay to Earth. Direct-to-Earth transmission may also be considered, which would be more convenient during the Saturn Tour Phase. A balloon provides an ideal platform for studying Titan's lower atmosphere in detail (e.g. Lorenz et al. 2008b). Penetrating the thick atmosphere to sound the troposphere and surface from orbit is extremely difficult otherwise. The balloon would be able to sample multiple altitudes in the $1-10 \mathrm{~km}$ range and by using Titan's winds and global circulation pattern could systematically cover many different latitudes and terrain types. Extremely high-resolution surface imaging could be performed, and the chemical composition of the aerosols and atmospheric gases could be directly sampled. Such measurements would be invaluable for interpreting orbital data, studying evolution of the atmosphere, and determining haze composition and the extent of the complex organic chemistry. Titan's low gravity and thick atmosphere make it an ideal candidate for a balloonbased mission.

\subsubsection{Strawman instrument payload}

Table 7 presents a tentative payload that would address the required measurements presented in Tables 4-6 for the science goals $\mathrm{A}, \mathrm{B}$, and $\mathrm{C}$. The proposed instruments will benefit from the heritage of previously successful missions such as CassiniHuygens as well as new missions currently under study (such as JUICE).
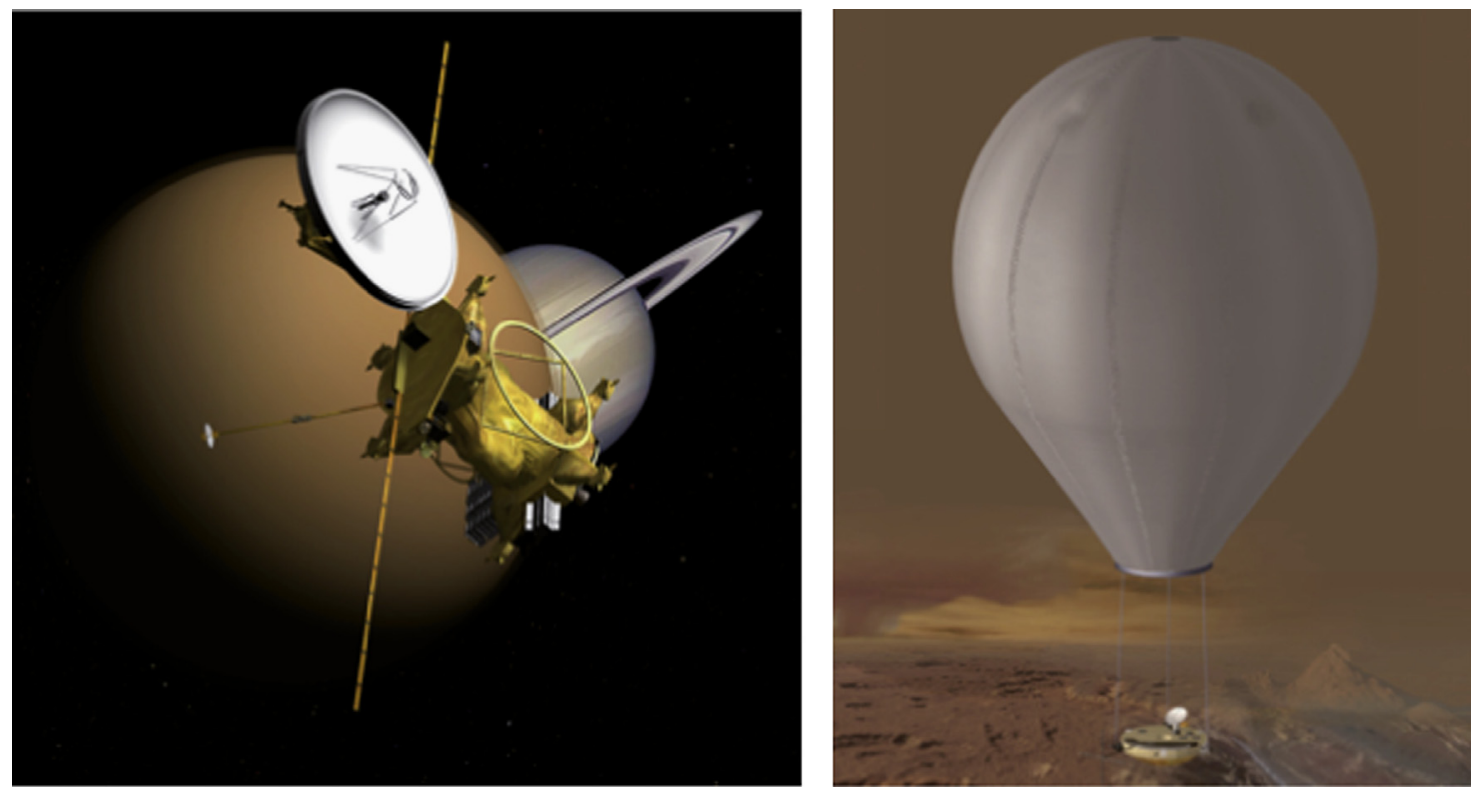

Fig. 5. Concepts of orbiter and hot air balloon considered for TSSM (Reh et al., 2009a). 


\subsubsection{Critical issues and technological developments}

Beyond Jupiter, a critical issue concerns the power source. At Saturn, solar power is very low and a long-term exploration mission as proposed here requires the use of radioisotope power sources. In the TSSM concept, MMRTGs or ASRGs using ${ }^{238} \mathrm{Pu}$ were considered and were to be provided by NASA. The developments of ASRGs have now been abandoned by NASA and the amount of available ${ }^{238} \mathrm{Pu}$ is now reduced. Within Europe, the radioisotope ${ }^{241} \mathrm{Am}$ is considered a feasible alternative to ${ }^{238} \mathrm{Pu}$ and can provide a heat source for small-scale radioisotope thermoelectric generators (RTGs) and radioisotope heating units (RHUs) (Tinsley et al., 2011). About $1000 \mathrm{~kg}$ of ${ }^{241} \mathrm{Am}$ exists in an isotopically pure state within stored civil plutonium at reprocessing sites within the UK and France. A study is underway to design a process that will chemically separate ${ }^{241} \mathrm{Am}$ (Sarsfield et al., 2012). The development of ${ }^{241} \mathrm{Am}$-based RTGs is under consideration by ESA and the first RTGs at high TRL may be available in about one decade.

Following the TSSM pre-selection in 2008, a feasibility study by CNES and JPL was initiated in order to optimize the design of a hot air balloon under Titan's conditions. The assessment was based on ${ }^{238} \mathrm{Pu}$-RTGs, which, in addition to providing electric power, were the heat source for generating buoyancy of the balloon. The possible use of ${ }^{241} \mathrm{Am}-\mathrm{RTG}$, which provide $20 \%$ less decay heat per unit mass, will require further assessment of the feasibility. A pressurized air balloon, as proposed in the TAE project, may also be considered as an alternative. A detailed comparison between the different approaches will be needed to determine the best option for in situ exploration of Titan's atmosphere. Instrumenting the balloon heat shield with abasic seismometer and possibly other lightweight instruments that would sit at the surface after landing was also considered in TSSM. Such options would require further study to evaluate their feasibility and utility. International collaboration, in the same spirit that what was done during the TSSM study, will be crucial to assess the feasibility of such mission and to develop the different elements needed to make such a mission successful.

\section{Conclusion and perspectives}

Titan and Enceladus are two extraordinary planetary objects, which the Cassini-Huygens mission have just started to unveil. In situ investigations of the two moons from orbit, and of Titan from an aerial platform, will provide a unique opportunity to solve several key questions that will remain unanswered by the CassiniHuygens mission:

- What is the chemical composition of Titan's aerosols?

- What are the dynamics of Titan's troposphere, and how does it affect the surface evolution?

- How do organic compounds evolve on Titan's surface, in lakes and in ice-rich regions?
- What processes drive the surface and plume activities on Enceladus?

- Does the plume contain complex molecules of astrobiological interest?

Most of these key questions can be addressed by the suite of instruments and measurements in the proposed mission concept. Sampling of Enceladus' plumes and remote sensing observations during successive close flybys before insertion around Titan will provide key data on the plume composition and its sources. For Titan, the orbiter will provide a global coverage which is essential to map the surface as well as the atmosphere dynamics and composition, and it will allow a direct sampling of the upper atmosphere during aerobreaking phases. The Titan balloon will provide crucial information inaccessible from the orbit by monitoring the troposphere dynamics and composition (aerosol and gas). It will be an ideal platform to acquire very high resolution images, offering spectacular views of the surface with unprecedented details all around the equatorial band, not only at a single location like Huygens. This mission concept will, however, address only partially the questions of lake and surface composition as no direct sampling of the surface is proposed. The composition will be addressed only from remote sensing data. Detailed determination of the lake composition requires a dedicated probe as described in Mitri et al., (2014). Ideally, a mission concept involving two in situ elements in addition to an orbiter, provided by several space agencies as proposed for TSSM, will be needed to fully address the main science questions highlighted here.

Although Titan, Enceladus and the Saturn system were not chosen as the science theme for the next ESA L-class missions (after JUICE), strong support from the scientific community clearly showed that the exploration of these two moons is a high-priority challenge in the future exploration of the Solar system. Many ideas for future exploration missions are now blooming. Although some key objectives may be addressed by medium-size "reconnaissance" missions (Discovery-class, Medium-class missions), an in-depth exploration of these moons will require a large and ambitious mission, involving a strong international cooperation in the same spirit that led to the highly successful Cassini-Huygens mission. A major goal for the next decade is to prepare for such an ambitious project by continuing to strengthen international collaboration among scientists and by convincing space agencies that international cooperation is the best way forward for future exploration of Titan and Enceladus, and more generally of the Outer Solar System.

To prepare for future exploration of Titan and Enceladus, a series of studies involving observations, instrumental development, laboratory experiments and theoretical modeling are needed. For Titan, a major objective for the future is to fully characterize the chemical composition and structure of atmospheric aerosols, and if possible at different altitudes. This requires the development of devices for collecting and analyzing aerosols from an aerial platform. Laboratory experiments on organic materials analogous to Titan's aerosols are needed to prepare

Table 7

Tentative instrument payload to address the three mission Goals A, B and C. The checkmarks indicate for each instrument the goal it can address.

\begin{tabular}{|c|c|c|c|c|c|c|}
\hline Saturn-Titan Orbiter & A & B & C & Titan Balloon & A $\mathbf{B}$ & C \\
\hline $\begin{array}{l}\text { 1. High-resolution imager }(2,2.7,5-6 \mu \mathrm{m}) \text { and Spectrometer } \\
(0.85-2.4 / 4.8-5.8 \mu \mathrm{m})\end{array}$ & $\checkmark$ & $\checkmark$ & $\checkmark$ & $\begin{array}{l}\text { 1. Visual imaging system (two wide angle stereo cameras and one narrow } \\
\text { angle camera) }\end{array}$ & $\checkmark$ & $\checkmark$ \\
\hline 2. Penetrating radar and altimeter $(>20 \mathrm{MHz})$ & $\checkmark$ & $\checkmark$ & $\checkmark$ & 2. Imaging spectrometer $(1-5.6 \sim \mu \mathrm{m})$ & $\checkmark$ & $\checkmark$ \\
\hline 3. Thermal Infrared Spectrometer $(7-333 \mu \mathrm{m})$ & $\checkmark$ & $\checkmark$ & $\checkmark$ & 3. Atmospheric structure instrument and meteorological package & $\checkmark$ & \\
\hline 4. High resolution mass spectrometer (up to $10,000 \mathrm{u}$.) & $\checkmark$ & $\checkmark$ & $\checkmark$ & 4. Electric environment package & $\checkmark$ & $\checkmark$ \\
\hline 5. Icy grain and organic dust analyzer & $\checkmark$ & $\checkmark$ & $\checkmark$ & 5. Radar sounder $(>150 \mathrm{MHz})$ & $\checkmark$ & $\checkmark$ \\
\hline 6. Plasma suite & $\checkmark$ & $\checkmark$ & $\checkmark$ & 6. Gas chromatograph mass spectrometer (1-600 u.) & $\checkmark$ & $\checkmark$ \\
\hline 7. Magnetometer & $\checkmark$ & $\checkmark$ & $\checkmark$ & 7. Radio science using spacecraft telecom system & $\checkmark$ & $\checkmark$ \\
\hline 8. Radio Science Experiment & $\checkmark$ & $\checkmark$ & $\checkmark$ & 8. Magnetometer & $\checkmark$ & $\checkmark$ \\
\hline 9. Sub-millimetre heterodyne & $\checkmark$ & $\checkmark$ & $\checkmark$ & & & \\
\hline 10. UV spectrometer & $\checkmark$ & $\checkmark$ & $\checkmark$ & & & \\
\hline
\end{tabular}


for their future in situ analysis and to anticipate the best instrumental strategy to determine their complex composition. More generally, laboratory studies on materials analogous to what is expected on Titan's surface (solid and liquid organics, hydrates, ices) are needed to determine their spectral, dielectric, thermo-mechanical properties, as well as their possible interactions with the atmosphere, through wind transport and evaporation/condensation/dissolution processes. Spectroscopic measurements of complex atmospheric gaseous and condensed ice-phase organics are also lacking, and will be essential for implementation of remote sensing measurements of their global distribution. Such measurements will allow evolution pathways to Titan's aerosols to be further constrained. Even though not directly mentioned in the present mission concept, possible collection of surface samples and onboard analysis could be envisioned. Here again, different analytical techniques should be tested and validated. Modeling of the atmosphere structure and dynamics, especially in the troposphere, for future balloon navigations is required. In addition a better understanding of the upper part of the atmosphere is needed to enable the potential future aero-sampling from an orbiter.

For Enceladus, one of the major objectives is to detect complex molecules in both the gas and the solid phase of the plume. Measurements performed by Cassini/INMS (Waite et al., 2011) indicated that, for elevated flyby velocities, collision processes with the instrument chamber can dissociate organic macromolecules and affect the determination of plume composition. Future investigations are needed to understand how complex organics may be sampled and analyzed during close flybys. Modeling efforts are also needed to better understand the connection between the jet and surface activities and to identify measurements that will allow the identification of the controlling mechanisms.

Support from national agencies will be essential in developing the new generation of highly capable instrumentation, as well as in pursuing experimental and modeling efforts initiated with Cassini-Huygens, in order to be ready for the next rendezvous with Titan and Enceladus.

\section{Acknowledgments}

The research leading to these results has received funding from the European Research Council under the European Community's Seventh Framework Programme (FP7/2007-2013 Grant agreement no. 259285), UK Science and Technology Facilities Council, Leverhulme Trust and CNES.

\section{Appendix A. Supplementary data}

Supplementary data associated with this article can be found in the online version at http://dx.doi.org/10.1016/j.pss.2014.10.002.

\section{References}

Achterberg, R.K., Conrath, B.J., Gierasch, P.J., Flasar, F.M., Nixon, C.A., 2008. Observation of a tilt of Titan's middle-atmospheric superrotation. Icarus 197, 549-555. Artemieva, N., Lunine, J., 2003. Cratering on Titan: impact melt, ejecta, and the fate of surface organics. Icarus 164, 471-480.

Baland, R.M., Tobie, G., Lefèvre, A., Van Hoolst, T., 2014. Titan's internal structure inferred from its gravity field, shape, and rotation state. Icarus 237, 29-41.

Baland, R.M., van Hoolst, T., Yseboodt, M., Karatekin, Ö., 2011. Titan's obliquity as evidence of a subsurface ocean? Astron. Astrophys. 530, A141.

Barnes, J.W., Bow, J., Schwartz. J., Brown, R.H., Soderblom, J.M., Hayes, A.G., Vixie, G., Le Mouélic, S., Rodriguez, S., Sotin, C., Jaumann, R., Stephan, K., Soderblom, L.A. Clark, R.N., Buratti, B.J., Baines, K.H., Nicholson, P.D., 2011. Organic sedimentary deposits in Titan's dry lakebeds: probable evaporite. Icarus 216, 136-140.

Barnes, J.W., Lemke, L., Foch, R., McKay, C.P., Beyer, R.A., Radebaugh, J., Atkinson, D.H., Lorenz, R.D., Le Mouélic, S., Rodriguez, S., Gundlach, J., Giannini, F., Bain, S., Flasar, F.M., Hurford, T., Anderson, C.M., Merrison, J., Ádámkovics, M., Kattenhorn, S.A., Mitchell, J., Burr, D.M., Colaprete, A., Schaller, E., Friedson, A.J., Edgett, K.S., Coradini, A., Adriani, A., Sayanagi, K.M., Malaska, M.J., Morabito, D., Reh, K., 2012.
AVIATR-aerial vehicle for in-situ and airborne Titan Reconnaissance. A Titan airplane mission concept. Exp. Astron. 33, 55-127.

Béghin, C., Randriamboarison, O., Hamelin, M., Karkoschka, E., Sotin, C., Whitten, R.C. Berthelier, J.J., Grard, R., Simões, F., 2012. Analytic theory of Titan's Schumann resonance: constraints on ionospheric conductivity and buried water ocean. Icarus 218, 1028-1042.

Bell, J.M., Hunter Waite, J., Westlake, J.H., Bougher, S.W., Ridley, A.J., Perryman, R., Mandt, K., 2014. Developing a self-consistent description of Titan's upper atmosphere without hydrodynamic escape. J. Geophys. Res. (Space Phys.) 119, 4957-4972.

Bézard, B., Yelle, R.V., Nixon, C.A., 2014. The composition of Titans atmosphere. In Müller-Wodarg, I., Griffith, C.A., Lellouch, E., Cravens, T.E. (Eds.), Titan: Interior Surface, Atmosphere, and Space Environment. Cambridge University Press, Cambridge, pp. 158-189.

Bird, M.K., Allison, M., Asmar, S.W., Atkinson, D.H., Avruch, I.M., Dutta-Roy, R. Dzierma, Y., Edenhofer, P., Folkner, W.M., Gurvits, L.I., Johnston, D.V., Plettemeier, D., Pogrebenko, S.V., Preston, R.A., Tyler, G.L., 2005. The vertical profile of winds on Titan. Nature 438, 800-802.

Brandt, P.C., Dialynas, K., Dandouras, I., Mitchell, D.G., Garnier, P., Krimigis, S.M. 2012. The distribution of Titanś high-altitude (out to $50,000 \mathrm{~km}$ ) exosphere from energetic neutral atom (ena) measurements by Cassini/inca. Plan. Space Sci. 60, 107-114.

Brown, R.H., Johnson, T.V., Kirk, R.L., Soderblom, L.A., 1990. Energy sources for Triton's geyser-like plumes. Science 250, 431-435.

Brown, R.H., Soderblom, L.A., Soderblom, J.M., Clark, R.N., Jaumann, R., Barnes, J.W. Sotin, C., Buratti, B., Baines, K.H., Nicholson, P.D., 2008. The identification of liquid ethane in Titan's Ontario Lacus. Nature 454, 607-610.

Burger, M.H., Sittler, E.C., Johnson, R.E., Smith, H.T., Tucker, O.J., Shematovich, V.I., 2007. Understanding the escape of water from Enceladus. J. Geophys. Res. 112 6219.

Cable, M.L., Hörst, S.M., Hodyss, R., Beauchamp, P.M., Smith, M.A., Willis, P.A., 2012 Titan tholins: simulating Titan organic chemistry in the Cassini-Huygens era. Chem. Rev. 112, 1882-1909.

Coates, A.J., 2009. Interaction of Titan's ionosphere with Saturn's magnetosphere Phil. Trans. R. Soc. Lond. A 367, 773-788.

Coates, A.J., Crary, F.J., Lewis, G.R., Young, D.T., Waite, J.H., Sittler, E.C., 2007. Discovery of heavy negative ions in Titan's ionosphere. Geophys. Res. Lett. 34 22103.

Coates, A.J., Wellbrock, A., Lewis, G.R., Jones, G.H., Young, D.T., Crary, F.J., Waite, J.H. Johnson, R.E., Hill, T.W., Sittler Jr., E.C., 2010. Negative ions at Titan and Enceladus: recent results. Faraday Discuss. 147, 293-305.

Coll, P., Navarro-González, R., Szopa, C., Poch, O., Ramírez, S.I., Coscia, D., Raulin, F. Cabane, M., Buch, A., Israël, G., 2013. Can laboratory tholins mimic the chemistry producing Titan's aerosols? A review in light of ACP experimental results. Plan. Space Sci. 77, 91-103.

Cordier, D., Mousis, O., Lunine, J.I., Lebonnois, S., Rannou, P., Lavvas, P., Lobo, L.Q. Ferreira, A.G.M., 2012. Titan's lakes chemical composition: sources of uncertainties and variability. Plan. Space Sci. 61, 99-107.

Cornet, T., Bourgeois, O., Le Mouélic, S., Rodriguez, S., Lopez Gonzalez, T., Sotin, C., Tobie, G., Fleurant, C., Barnes, J.W., Brown, R.H., Baines, K.H., Buratti, B.J., Clark, R.N., Nicholson, P.D., 2012. Geomorphological significance of Ontario lacus on titan: integrated interpretation of Cassini vims, iss and radar data and comparison with the etosha pan (namibia). Icarus 218, 788-806.

Cours, T., Burgalat, J., Rannou, P., Rodriguez, S., Brahic, A., West, R.A., 2011. Dua origin of aerosols in Titan's detached Haze layer. Astrophys. J. Lett. 741, L32.

Coustenis, A., Achterberg, R.K., Conrath, B.J., Jennings, D.E., Marten, A., Gautier, D. Nixon, C.A., Flasar, F.M., Teanby, N.A., Bézard, B., Samuelson, R.E., Carlson, R.C. Lellouch, E., Bjoraker, G.L., Romani, P.N., Taylor, F.W., Irwin, P.G.J., Fouchet, T. Hubert, A., Orton, G.S., Kunde, V.G., Vinatier, S., Mondellini, J., Abbas, M.M., Courtin, R., 2007. The composition of Titan's stratosphere from Cassini/CIRS midinfrared spectra. Icarus 189, 35-62.

Coustenis, A., Atreya, S.K., Balint, T., Brown, R.H., Dougherty, M.K., Ferri, F., Fulchignoni, M., Gautier, D., Gowen, R.A., Griffith, C.A., Gurvits, L.I., Jaumann, R., Langevin, Y., Leese, M.R., Lunine, J.I., McKay, C.P., Moussas, X., Müller-Wodarg, I., Neubauer, F., Owen, T.C., Raulin, F., Sittler, E.C., Sohl, F., Sotin, C., Tobie, G., Tokano, T., Turtle, E.P., Wahlund, J.E., Waite, J.H., Baines, K.H., Blamont, J. Coates, A.J., Dandouras, I., Krimigis, T., Lellouch, E., Lorenz, R.D., Morse, A., Porco, C.C., Hirtzig, M., Saur, J., Spilker, T., Zarnecki, J.C., Choi, E., Achilleos, N. Amils, R., Annan, P., Atkinson, D.H., Bénilan, Y., Bertucci, C., Bézard, B., Bjoraker, G.L. Blanc, M., Boireau, L., Bouman, J., Cabane, M., Capria, M.T., Chassefière, E., Coll, P., Combes, M., Cooper, J.F., Coradini, A., Crary, F., Cravens, T., Daglis, I.A., de Angelis, E. de Bergh, C., de Pater, I., Dunford, C., Durry, G., Dutuit, O., Fairbrother, D., Flasar, F.M., Fortes, A.D., Frampton, R., Fujimoto, M., Galand, M., Grasset, O., Grott, M. Haltigin, T., Herique, A., Hersant, F., Hussmann, H., Ip, W., Johnson, R., Kallio, E. Kempf, S., Knapmeyer, M., Kofman, W. Koop, R, Kostiuk, T, Krupp, N., Küppers, M. Lammer, H., Lara, L.M., Lavvas, P., Le Mouélic, S., Lebonnois, S., Ledvina, S., Li, J. Livengood, T.A., Lopes, R.M., Lopez-Moreno, J.J., Luz, D., Mahaffy, P.R., Mall, U., Martinez-Frias, J., Marty, B., McCord, T., Menor Salvan, C., Milillo, A., Mitchell, D.G., Modolo, R. Mousis, O. Nakamura, M., Neish, C.D., Nixon, C.A., Nna Mvondo, D. Orton, G., Paetzold, M., Pitman, J., Pogrebenko, S., Pollard, W., Prieto-Ballesteros, O. Rannou, P., Reh, K., Richter, L., Robb, F.T., Rodrigo, R., Rodriguez, S., Romani, P., Ruiz Bermejo, M., Sarris, E.T., Schenk, P., Schmitt, B., Schmitz, N., Schulze-Makuch, D. Schwingenschuh, K., Selig, A., Sicardy, B., Soderblom, L., Spilker, L.J., Stam, D. Steele, A., Stephan, K., Strobel, D.F., Szego, K., Szopa, C., Thissen, R., Tomasko, M.G., Toublanc, D., Vali, H., Vardavas, I., Vuitton, V., West, R.A., Yelle, R., Young, E.F., 2009. TandEM: Titan and Enceladus mission. Exp. Astron. 23, 893-946. 
Coustenis, A., Hirtzig, M., Gendron, E., Drossart, P., Lai, O., Combes, M., Negrão, A. 2005. Maps of Titan's surface from 1 to $2.5 \mu \mathrm{m}$. Icarus 177, 89-105.

Coustenis, A., Jennings, D.E., Nixon, C.A., Achterberg, R.K., Lavvas, P., Vinatier, S., Teanby, N.A., Bjoraker, G.L., Carlson, R.C., Piani, L., Bampasidis, G., Flasar, F.M., Romani, P.N., 2010. Titan trace gaseous composition from CIRS at the end of the Cassini-Huygens prime mission. Icarus 207, 461-476.

Crary, F.J., Magee, B.A., Mandt, K., Waite, J.H., Westlake, J., Young, D.T., 2009. Heavy ions, temperatures and winds in Titan's ionosphere: combined Cassini CAPS and INMS observations. Plan. Space Sci. 57, 1847-1856.

Crow-Willard, E.N., Pappalardo, R.T., 2010. Global geological mapping of Enceladus. In: Lunar and Planetary Institute Science Conference Abstracts, p. 2715

Dougherty, M.K., Khurana, K.K., Neubauer, F.M., Russell, C.T., Saur, J., Leisner, J.S. Burton, M.E., 2006. Identification of a dynamic atmosphere at Enceladus with the Cassini magnetometer. Science 311, 1406-1409.

Flasar, F.M., Achterberg, R.K., Conrath, B.J., Gierasch, P.J., Kunde, V.G., Nixon, C.A., Bjoraker, G.L., Jennings, D.E., Romani, P.N., Simon-Miller, A.A., Bézard, B., Coustenis, A., Irwin, P.G.J., Teanby, N.A., Brasunas, J., Pearl, J.C., Segura, M.E., Carlson, R.C., Mamoutkine, A., Schinder, P.J., Barucci, A., Courtin, R., Fouchet, T., Gautier, D., Lellouch, E., Marten, A., Prangé, R., Vinatier, S., Strobel, D.F., Calcutt, S.B., Read, P.L., Taylor, F.W., Bowles, N., Samuelson, R.E., Orton, G.S. Spilker, L.J., Owen, T.C., Spencer, J.R., Showalter, M.R., Ferrari, C., Abbas, M.M. Raulin, F., Edgington, S., Ade, P., Wishnow, E.H., 2005. Titan's atmospheric temperatures, winds, and composition. Science 308, 975-978.

Flasar, F.M., Baines, K.H., Bird, M.K., Tokano, T., West, R.A., 2009. Atmospheric dynamics and meteorology. In: Brown, R.H., Lebreton, J.P., Waite, J.H. (Eds.), Titan from Cassini-Huygens. Springer, New York, pp. 323-352.

Fleshman, B.L., Delamere, P.A., Bagenal, F., 2010. Modeling the Enceladus plumeplasma interaction. Geophys. Res. Lett. 37, 3202.

Fortes, A.D., 2000. Exobiological implications of a possible ammonia-water ocean inside Titan. Icarus 146, 444-452.

Fortes, A.D., Grindrod, P.M., 2006. Modelling of possible mud volcanism on Titan. Icarus 182, 550-558.

Fortes, A.D., Grindrod, P.M., Trickett, S.K., Vočadlo, L., 2007. Ammonium sulfate on Titan: possible origin and role in cryovolcanism. Icarus 188, 139-153.

Fulchignoni, M., Ferri, F., Angrilli, F., Ball, A.J., Bar-Nun, A., Barucci, M.A., Bettanini, C. Bianchini, G., Borucki, W., Colombatti, G., Coradini, M., Coustenis, A., Debei, S. Falkner, P., Fanti, G., Flamini, E., Gaborit, V., Grard, R., Hamelin, M., Harri, A.M., Hathi, B., Jernej, I., Leese, M.R., Lehto, A., Lion Stoppato, P.F., López-Moreno, J.J. Mäkinen, T., McDonnell, J.A.M., McKay, C.P., Molina-Cuberos, G., Neubauer, F.M., Pirronello, V., Rodrigo, R., Saggin, B., Schwingenschuh, K., Seiff, A., Simões, F., Svedhem, H., Tokano, T., Towner, M.C., Trautner, R., Withers, P., Zarnecki, J.C., 2005. In situ measurements of the physical characteristics of Titan's environment. Nature 438, 785-791.

Gautier, T., Carrasco, N., Schmitz-Afonso, I., Touboul, D., Szopa, C., Buch, A., Pernot, P. 2014. Nitrogen incorporation in Titan's tholins inferred by high resolution orbitrap mass spectrometry and gas chromatography-mass spectrometry. Earth Planet. Sci. Lett. 404, 33-42.

Gudipati, M.S., Jacovi, R., Couturier-Tamburelli, I., Lignell, A., Allen, M., 2013. Photochemical activity of Titan's low-altitude condensed haze. Nat Commun 4, 1-8.

Hansen, C.J., Esposito, L.W., Stewart, A.I.F., Meinke, B., Wallis, B., Colwell, J.E., Hendrix, A.R., Larsen, K., Pryor, W., Tian, F., 2008. Water vapour jets inside the plume of gas leaving Enceladus. Nature 456, 477-479.

Hansen, C.J., Shemansky, D.E., Esposito, L.W., Stewart, A.I.F., Lewis, B.R., Colwell, J.E. Hendrix, A.R., West, R.A., Waite Jr., J.H., Teolis, B., Magee, B.A., 2011. The composition and structure of the Enceladus plume. Geophys. Res. Lett. 38, 11202.

Hayes, A., Aharonson, O., Callahan, P., Elachi, C., Gim, Y., Kirk, R., Lewis, K., Lopes, R. Lorenz, R., Lunine, J., Mitchell, K., Mitri, G., Stofan, E., Wall, S., 2008. Hydrocarbon lakes on Titan: distribution and interaction with a porous regolith Geophys. Res. Lett. 35, 9204

Hedman, M.M., Gosmeyer, C.M., Nicholson, P.D., Sotin, C., Brown, R.H., Clark, R.N. Baines, K.H., Buratti, B.J., Showalter, M.R., 2013. An observed correlation between plume activity and tidal stresses on Enceladus. Nature 500, 182-184.

Hedman, M.M., Nicholson, P.D., Showalter, M.R., Brown, R.H., Buratti, B.J., Clark, R.N., 2009. Spectral observations of the Enceladus plume with Cassini-Vims. Astrophys. J. 693, 1749-1762.

Hemingway, D., Nimmo, F., Zebker, H., Iess, L., 2013. A rigid and weathered ice shell on Titan. Nature 500, 550-552.

Hillier, J.K., Green, S.F., McBride, N., Schwanethal, J.P., Postberg, F., Srama, R., Kempf, S., Moragas-Klostermeyer, G., McDonnell, J.A.M., Grün, E., 2007. The composition of Saturn's E ring. Mon. Not. R. Astron. Soc. 377, 1588-1596.

Hinson, D.P., Tyler, G.L., 1983. Internal gravity-waves in Titan's atmosphere observed by Voyager radio occultation. Icarus 54, 337-352.

Hörst, S.M., Yelle, R.V., Buch, A., Carrasco, N., Cernogora, G., Dutuit, O., Quirico, E. Sciamma-O'Brien, E., Smith, M.A., Somogyi, Á., Szopa, C., Thissen, R., Vuitton, V. 2012. Formation of amino acids and nucleotide bases in a Titan atmosphere simulation experiment. Astrobiology 12, 809-817.

Howett, C.J.A., Spencer, J.R., Pearl, J., Segura, M., 2011. High heat flow from Enceladus' south polar region measured using 10-600 $\mathrm{cm}^{-1}$ Cassini/CIRS data. J. Geophys. Res. 116, 3003.

Hsu, H.W., Kempf, S., Postberg, F., Trieloff, M., Burton, M., Roy, M., MoragasKlostermeyer, G., Srama, R., 2011. Cassini dust stream particle measurements during the first three orbits at Saturn. J. Geophys. Res. 116, 8213.

Hurford, T.A., Helfenstein, P., Spitale, J.N., 2012. Tidal control of jet eruptions on Enceladus as observed by Cassini ISS between 2005 and 2007. Icarus 220, 896-903.
Iess, L., Jacobson, R.A., Ducci, M., Stevenson, D.J., Lunine, J.I., Armstrong, J.W., Asmar, S.W., Racioppa, P., Rappaport, N.J., Tortora, P., 2012. The tides of Titan. Science 337, 457-459.

Iess, L., Stevenson, D.J., Parisi, M., Hemingway, D., Jacobson, R.A., Lunine, J.I., Nimmo, F., Armstrong, J.W., Asmar, S.W., Ducci, M., Tortora, P., 2014. The gravity field and interior structure of Enceladus. Science 344, 78-80.

Ingersoll, A.P., Ewald, S.P., 2011. Total particulate mass in Enceladus plumes and mass of Saturn's E ring inferred from Cassini ISS images. Icarus 216, 492-506.

Israël, G. Szopa, C. Raulin, F Cabane, M. Niemann, H.B. Atreya, S.K. Bauer, S.J. Brun, J.F., Chassefière, E., Coll, P., Condé, E., Coscia, D., Hauchecorne, A., Millian, P., Nguyen, M.J., Owen, T., Riedler, W., Samuelson, R.E., Siguier, J.M., Steller, M., Sternberg, R., VidalMadjar, C., 2005. Complex organic matter in Titan's atmospheric aerosols from in situ pyrolysis and analysis. Nature 438, 796-799.

Jaumann, R., Brown, R.H., Stephan, K., Barnes, J.W., Soderblom, L.A., Sotin, C., Le Mouélic, S., Clark, R.N., Soderblom, J., Buratti, B.J., Wagner, R., McCord, T.B., Rodriguez, S., Baines, K.H., Cruikshank, D.P., Nicholson, P.D., Griffith, C.A., Langhans, M., Lorenz, R.D., 2008. Fluvial erosion and post-erosional processes on Titan. Icarus 197, 526-538.

Jaumann, R., Kirk, R.L., Lorenz, R.D., Lopes, R.M.C., Stofan, E., Turtle, E.P., Keller, H.U., Wood, C.A., Sotin, C., Soderblom, L.A., Tomasko, M., 2009. Geology and surface processes on Titan. In: Brown, R.H., Lebreton, J.P., Waite, J.H. (Eds.), Titan from Cassini-Huygens. Springer, New York, pp. 75-140.

Jia, Y.D., Russell, C.T., Khurana, K.K., Leisner, J.S., Ma, Y.J., Dougherty, M.K., 2010. Time-varying magnetospheric environment near Enceladus as seen by the Cassini magnetometer. Geophys. Res. Lett. 37, 9203.

Jones, G.H., Arridge, C.S., Coates, A.J., Lewis, G.R., Kanani, S., Wellbrock, A., Young, D.T., Crary, F.J., Tokar, R.L., Wilson, R.J., Hill, T.W., Johnson, R.E., Mitchell, D.G., Schmidt, J., Kempf, S., Beckmann, U., Russell, C.T., Jia, Y.D., Dougherty, M.K., Waite, J.H., Magee, B.A., 2009. Fine jet structure of electrically charged grains in Enceladus' plume. Geophys, Res, Lett. 36, 16204.

Keller, H.U., Grieger, B., Küppers, M., Schröder, S.E., Skorov, Y.V., Tomasko, M.G., 2008. The properties of Titan's surface at the Huygens landing site from DISR observations. Plan. \& Space Sci. 56, 728-752.

Kempf, S., Beckmann, U., Schmidt, J., 2010. How the Enceladus dust plume feeds Saturn's E ring. Icarus 206, 446-457.

Kirchoff, M.R., Schenk, P., 2009. Crater modification and geologic activity in Enceladus' heavily cratered plains: evidence from the impact crater distribution. Icarus 202, 656-668.

Kirk, R.L., Soderblom, L.A., Brown, R.H., 1990. Subsurface energy storage and transport for solar-powered geysers on Triton. Science 250, 424-429.

Kriegel, H., Simon, S., Motschmann, U., Saur, J., Neubauer, F.M., Persoon, A.M., Dougherty, M.K., Gurnett, D.A., 2011. Influence of negatively charged plume grains on the structure of Enceladus' Alfvén wings: hybrid simulations versus Cassini Magnetometer data. J. Geophys. Res. 116, 10223.

Kriegel, H., Simon, S., Müller, J., Motschmann, U., Saur, J., Glassmeier, K.H., Dougherty, M.K., 2009. The plasma interaction of Enceladus: 3D hybrid simulations and comparison with Cassini MAG data. Plan. Space Sci. 57, 2113-2122.

Langhans, M., Lunine, J.I., Mitri, G., 2013. Titan's Xanadu region: geomorphology and formation scenario. Icarus 223, 796-803.

Langhans, M.H., Jaumann, R., Stephan, K., Brown, R.H., Buratti, B.J., Clark, R.N., Baines, K.H., Nicholson, P.D., Lorenz, R.D., Soderblom, L.A., Soderblom, J.M., Sotin, C., Barnes, J.W., Nelson, R., 2012. Titan's fluvial valleys: morphology, distribution, and spectral properties. Plan. Space Sci. 60, 34-51.

Lavvas, P., Yelle, R.V., Koskinen, T., Bazin, A., Vuitton, V., Vigren, E., Galand, M., Wellbrock, A., Coates, A.J., Wahlund, J.E., Crary, F.J., Snowden, D., 2013. Aerosol growth in Titan's ionosphere. Proc. Natl. Acad. Sci. 110, 2729-2734.

Lavvas, P.P., Coustenis, A., Vardavas, I.M., 2008. Coupling photochemistry with haze formation in Titan's atmosphere, Part I: model description. Plan. Space Sci. 56, 27-66.

Le Mouélic, S., Rannou, P., Rodriguez, S., Sotin, C., Griffith, C.A., Le Corre, L., Barnes, J.W., Brown, R.H., Baines, K.H., Buratti, B.J., Clark, R.N., Nicholson, P.D., Tobie, G., 2012. Dissipation of Titan's north polar cloud at northern spring equinox. Plan. Space Sci. $60,86-92$.

Lefevre, A., Tobie, G., Choblet, G., Čadek, O., 2014. Structure and dynamics of titan's outer icy shell constrained from Cassini data. Icarus 237, 16-28.

Lopes, R.M.C., Kirk, R.L., Mitchell, K.L., Legall, A., Barnes, J.W., Hayes, A., Kargel, J., Wye, L., Radebaugh, J., Stofan, E.R., Janssen, M.A., Neish, C.D., Wall, S.D., Wood, C.A., Lunine, J.I. Malaska, M.J. 2013. Cryovolcanism on Titan: new results from Cassini RADAR and VIMS. J. Geophys. Res. 118, 416-435.

Lopes, R.M.C., Mitchell, K.L., Stofan, E.R., Lunine, J.I., Lorenz, R., Paganelli, F., Kirk, R.L., Wood, C.A., Wall, S.D., Robshaw, L.E., Fortes, A.D. Neish, C.D., Radebaugh, J., Reffet, E., Ostro, S.J., Elachi, C., Allison, M.D., Anderson, Y., Boehmer, R., Boubin, G., Callahan, P. Encrenaz, P., Flamini, E., Francescetti, G., Gim, Y., Hamilton, G., Hensley, S., Janssen, M.A., Johnson, W.T.K., Kelleher, K., Muhleman, D.O., Ori, G., Orosei, R. Picardi, G. Posa, F, Roth, LE, Seu, R, Shaffer, S, Soderblom, LA, Stiles, B, Vetrella, S. West, R.D., Wye, L., Zebker, H.A., 2007. Cryovolcanic features on Titan's surface as revealed by the Cassini Titan Radar Mapper. Icarus 186, 395-412.

Lopes, R.M.C., Stofan, E.R., Peckyno, R., Radebaugh, J., Mitchell, K.L., Mitri, G., Wood, C.A., Kirk, R.L., Wall, S.D., Lunine, J.I., Hayes, A., Lorenz, R., Farr, T., Wye, L., Craig, J., Ollerenshaw, R.J., Janssen, M., Legall, A., Paganelli, F., West, R., Stiles, B., Callahan, P., Anderson, Y., Valora, P., Soderblom, L., The Cassini Radar Team, 2010. Distribution and interplay of geologic processes on Titan from Cassini radar data. Icarus 205, 540-558.

Lorenz, R.D., Leary, J.C., Lockwood, M.K., Waite, J.H., 2008a. Titan explorer: a NASA flagship mission concept. In: El-Genk, M.S. (Ed.), Space Technology and Applications International Forum-STAIF 2008, pp. 380-387. 
Lorenz, R.D., Lopes, R.M., Paganelli, F., Lunine, J.I., Kirk, R.L., Mitchell, K.L., Soderblom, L.A., Stofan, E.R., Ori, G., Myers, M., Miyamoto, H., Radebaugh, J., Stiles, B., Wall, S.D., Wood, C.A., The Cassini Radar Team, 2008. Fluvial channels on Titan: initial Cassini RADAR observations. Plan. Space Sci. 56, 1132-1144.

Lorenz, R.D., Wall, S., Radebaugh, J., Boubin, G., Reffet, E., Janssen, M., Stofan, E., Lopes, R., Kirk, R., Elachi, C., Lunine, J., Mitchell, K., Paganelli, F., Soderblom, L. Wood, C., Wye, L., Zebker, H., Anderson, Y., Ostro, S., Allison, M., Boehmer, R., Callahan, P., Encrenaz, P., Ori, G.G., Francescetti, G., Gim, Y., Hamilton, G., Hensley, S., Johnson, W., Kelleher, K., Muhleman, D., Picardi, G., Posa, F., Roth, L., Seu, R., Shaffer, S., Stiles, B., Vetrella, S., Flamini, E., West, R., 2006. The sand seas of Titan: Cassini RADAR observations of longitudinal dunes. Science 312, 724-727.

Lunine, J., Choukroun, M., Stevenson, D., Tobie, G., 2009. The origin and evolution of Titan. In: Brown, R.H., Lebreton, J.P., Waite, J.H. (Eds.), Titan from CassiniHuygens. Springer, New York, pp. 35-60.

Lunine, J.I., Reh, K., Sotin, C., Couzin, P., Vargas, A., 2011. Titan aerial explorer: a mission to circumnavigate Titan. In: Lunar and Planetary Institute Science Conference Abstracts, p. 1230.

Mandt, K.E., Waite, J.H., Teolis, B., Magee, B.A., Bell, J., Westlake, J.H., Nixon, C.A., Mousis, O., Lunine, J.I., 2012. The ${ }^{12} \mathrm{C} /{ }^{13} \mathrm{C}$ ratio on Titan from Cassini INMS measurements and implications for the evolution of methane. Astrophys. J. 749, 160.

Mastrogiuseppe, M., Poggiali, V., Hayes, A., Lorenz, R., Lunine, J., Picardi, G., Seu, R., Flamini, E., Mitri, G., Notarnicola, C., Paillou, P., Zebker, H., 2014. The bathymetry of a Titan sea. Geophys. Res. Lett. 41, 1432-1437.

Matson, D.L., Castillo-Rogez, J.C., Davies, A.G., Johnson, T.V., 2012. Enceladus: a hypothesis for bringing both heat and chemicals to the surface. Icarus 221, 53-62.

McKay, C.P., Porco Carolyn, C., Altheide, T., Davis, W.L., Kral, T.A., 2008. The possible origin and persistence of life on Enceladus and detection of biomarkers in the plume. Astrobiology 8, 909-919.

McKay, C.P., Smith, H.D., 2005. Possibilities for methanogenic life in liquid methane on the surface of Titan. Icarus 178, 274-276.

Mitchell, J.L., Ádámkovics, M., Caballero, R., Turtle, E.P., 2011. Locally enhanced precipitation organized by planetary-scale waves on Titan. Nat. Geosci. 4, 589-592.

Mitri, G., Bland, M.T., Showman, A.P., Radebaugh, J., Stiles, B., Lopes, R.M.C., Lunine, J.I., Pappalardo, R.T., 2010. Mountains on Titan: modeling and observations. J. Geophys. Res. 115, 10002.

Mitri, G., Meriggiola, R., Hayes, A., Lefevre, A., Tobie, G., Genova, A., Lunine, J.I., Zebker, H., 2014. Shape, topography, gravity anomalies and tidal deformation of Titan. Icarus 236, 169-177.

Moore, J.M., Pappalardo, R.T., 2011. Titan: an exogenic world?. Icarus 212, 790-806.

Neish, C.D., Lorenz, R.D., 2012. Titan's global crater population: a new assessment. Plan. Space Sci. 60, 26-33.

Neish, C.D., Lorenz, R.D., 2014. Elevation distribution of Titan's craters suggests extensive wetlands. Icarus 228, 27-34.

Niemann, H.B., Atreya, S.K., Bauer, S.J., Carignan, G.R., Demick, J.E., Frost, R.L., Gautier, D., Haberman, J.A., Harpold, D.N., Hunten, D.M., Israel, G., Lunine, J.I., Kasprzak, W.T., Owen, T.C., Paulkovich, M., Raulin, F., Raaen, E., Way, S.H., 2005. The abundances of constituents of Titan's atmosphere from the GCMS instrument on the Huygens probe. Nature 438, 779-784.

Niemann, H.B., Atreya, S.K., Demick, J.E., Gautier, D., Haberman, J.A., Harpold, D.N., Kasprzak, W.T., Lunine, J.I., Owen, T.C., Raulin, F., 2010. Composition of Titan's lower atmosphere and simple surface volatiles as measured by the CassiniHuygens probe gas chromatograph mass spectrometer experiment. J. Geophys. Res. 115, 12006

Nimmo, F., Bills, B.G., 2010. Shell thickness variations and the long-wavelength topography of Titan. Icarus 208, 896-904.

Nimmo, F., Porco, C., Mitchell, C., 2014. Tidally modulated eruptions on Enceladus: Cassini ISS observations and models. Astron. J. 148, 46

Nimmo, F., Spencer, J.R., Pappalardo, R.T., Mullen, M.E., 2007. Shear heating as the origin of the plumes and heat flux on Enceladus. Nature 447, 289-291.

Nixon, C.A., Achterberg, R.K., Vinatier, S., Bézard, B., Coustenis, A., Irwin, P.G.J., Teanby, N.A., de Kok, R., Romani, P.N., Jennings, D.E., Bjoraker, G.L., Flasar, F.M., 2008. The presup $12 C /{ }^{13} \mathrm{C}$ isotopic ratio in Titan hydrocarbons from Cassini/CIRS infrared spectra. Icarus 195, 778-791.

Nixon, C.A., Temelso, B., Vinatier, S., Teanby, N.A., Bézard, B., Achterberg, R.K., Mandt, K.E., Sherrill, C.D., Irwin, P.G.J., Jennings, D.E., Romani, P.N., Coustenis, A. Flasar, F.M., 2012. Isotopic ratios in Titan's Methane: measurements and modeling. Astrophys. J. 749, 159.

Norman, L.H., Fortes, A.D., 2011. Is there life on ... Titan? Astron. Geophys. 52. $39-42$.

Perron, J.T., Lamb, M.P., Koven, C.D., Fung, I.Y., Yager, E., Ádámkovics, M., 2006. Valley formation and methane precipitation rates on Titan. J. Geophys. Res. 111, 11001.

Poch, O., Coll, P., Buch, A., Ramírez, S.I., Raulin, F., 2012. Production yields of organics of astrobiological interest from $\mathrm{H}_{2} \mathrm{O}-\mathrm{NH}_{3}$ hydrolysis of Titan's tholins. Plan. Space Sci. 61, 114-123.

Porco, C., DiNino, D., Nimmo, F., 2014. How the Geysers, tidal stresses, and thermal emission across the South Polar Terrain of Enceladus are related. Astron. J. 148, 45

Porco, C.C., Baker, E., Barbara, J., Beurle, K., Brahic, A., Burns, J.A., Charnoz, S., Cooper, N., Dawson, D.D., Del Genio, A.D., Denk, T., Dones, L., Dyudina, U., Evans, M.W., Fussner, S., Giese, B., Grazier, K., Helfenstein, P., Ingersoll, A.P., Jacobson, R.A., Johnson, T.V., McEwen, A., Murray, C.D., Neukum, G., Owen, W.M., Perry, J. Roatsch, T., Spitale, J., Squyres, S., Thomas, P., Tiscareno, M., Turtle, E.P.,
Vasavada, A.R., Veverka, J., Wagner, R., West, R., 2005. Imaging of Titan from the Cassini spacecraft. Nature 434, 159-168.

Porco, C.C., Helfenstein, P., Thomas, P.C., Ingersoll, A.P., Wisdom, J., West, R. Neukum, G., Denk, T., Wagner, R., Roatsch, T., Kieffer, S., Turtle, E., McEwen, A. Johnson, T.V., Rathbun, J., Veverka, J., Wilson, D., Perry, J., Spitale, J., Brahic, A., Burns, J.A., Del Genio, A.D., Dones, L., Murray, C.D., Squyres, S., 2006. Cassini observes the active South Pole of Enceladus. Science 311, 1393-1401.

Postberg, F., Kempf, S., Hillier, J.K., Srama, R., Green, S.F., McBride, N., Grün, E., 2008 The E-ring in the vicinity of Enceladus. II. Probing the moon's interior-the composition of E-ring particles. Icarus 193, 438-454.

Postberg, F., Kempf, S., Schmidt, J., Brilliantov, N., Beinsen, A., Abel, B., Buck, U. Srama, R., 2009. Sodium salts in E-ring ice grains from an ocean below the surface of Enceladus. Nature 459, 1098-1101.

Postberg, F., Schmidt, J., Hillier, J., Kempf, S., Srama, R., 2011. A salt-water reservoir as the source of a compositionally stratified plume on Enceladus. Nature 474 620-622.

Radebaugh, J., Lorenz, R.D., Kirk, R.L., Lunine, J.I., Stofan, E.R., Lopes, R.M.C., Wall, S.D. the Cassini Radar Team, 2007. Mountains on Titan observed by Cassini Radar Icarus 192, 77-91.

Radebaugh, J., Lorenz, R.D., Lunine, J.I., Wall, S.D., Boubin, G., Reffet, E., Kirk, R.L. Lopes, R.M., Stofan, E.R., Soderblom, L., Allison, M., Janssen, M., Paillou, P. Callahan, P., Spencer, C., the Cassini Radar Team, 2008. Dunes on Titan observed by Cassini Radar. Icarus 194, 690-703.

Radebaugh, J., Lorenz, R.D., Wall, S.D., Kirk, R.L., Wood, C.A., Lunine, J.I., Stofan, E.R. Lopes, R.M.C., Valora, P., Farr, T.G., Hayes, A., Stiles, B., Mitri, G., Zebker, H. Janssen, M., Wye, L., LeGall, A., Mitchell, K.L., Paganelli, F., West, R.D., Schaller, E.L., Cassini Radar Team, 2011. Regional geomorphology and history of Titan's Xanadu province. Icarus 211, 672-685.

Raulin, F., Brassé, C., Poch, O., Coll, P., 2012. Prebiotic-like chemistry on Titan. Chem. Soc. Rev. 41, 5380-5393.

Reh, F., Erd, C., Matson, D., Coustenis, A., Lunine, J., Lebreton, J.P., The TSSM Joint Definition Team, 2009a. Tssm Final Report on the NASA Contribution to a Joint Mission with ESA, 3 November 2008, jpl d-48148. NASA Task Order, NM0710851.

Reh, F., Erd, C., Matson, D., Coustenis, A., Lunine, J., Lebreton, J.P., The TSSM Joint Definition Team, 2009b. Tssm NASA/ESA Joint Summary Report, 15 November 2008, esa-sre (2008) 3, jpl d-48442. NASA Task Order, NMO710851.

Rodriguez, S., Le Mouélic, S., Rannou, P., Sotin, C., Brown, R.H., Barnes, J.W., Griffith, C.A., Burgalat, J., Baines, K.H., Buratti, B.J., Clark, R.N., Nicholson, P.D., 2011. Titan's cloud seasonal activity from winter to spring with Cassini/VIMS. Icarus 216, 89-110.

Rodriguez, S., Le Mouélic, S., Rannou, P., Tobie, G., Baines, K.H., Barnes, J.W., Griffith, C.A., Hirtzig, M., Pitman, K.M., Sotin, C., Brown, R.H., Buratti, B.J., Clark, R.N. Nicholson, P.D., 2009. Global circulation as the main source of cloud activity on Titan. Nature 459, 678-682.

Roman, M.T., West, R.A., Banfield, D.J., Gierasch, P.J., Achterberg, R.K., Nixon, C.A., Thomas, P.C., 2009. Determining a tilt in Titan's north-south albedo asymmetry from Cassini images. Icarus 203, 242-249.

Roth, L., Saur, J., Retherford, K.D., Strobel, D.F., Feldman, P.D., McGrath, M.A., Nimmo, F., 2014. Transient water vapor at Europa's south pole. Science 343, 171-174.

Sarsfield, M., Bell, K., Maher, C., Carrott, M., Gregson, C., Brown, J., Woodhead, D. Baker, S., Cordingley, L., Taylor, R., Tinsley, T., Rice, T., 2012. A European radioisotope production facility for power sources in space. In: European Nuclear Conference, Manchester, pp. 4-8 (Non-power Industrial Applications).

Schenk, P., Hamilton, D.P., Johnson, R.E., McKinnon, W.B., Paranicas, C., Schmidt, J., Showalter, M.R., 2011. Plasma, plumes and rings: Saturn system dynamics as recorded in global color patterns on its midsize icy satellites. Icarus 211 $740-757$.

Schenk, P.M., McKinnon, W.B., 2009. One-hundred-km-scale basins on Enceladus: evidence for an active ice shell. Geophys. Res. Lett. 36, 16202.

Schmidt, J., Brilliantov, N., Spahn, F., Kempf, S., 2008. Slow dust in Enceladus' plume from condensation and wall collisions in tiger stripe fractures. Nature 451, 685-688.

Schulze-Makuch, D., Grinspoon, D.H., 2005. Biologically enhanced energy and carbon cycling on Titan? Astrobiology 5, 560-567.

Sebree, J.A., Trainer, M.G., Loeffler, M.J., Anderson, C.M., 2014. Titan aerosol analog absorption features produced from aromatics in the far infrared. Icarus 236, $146-152$.

Shafiq, M., Wahlund, J.E., Morooka, M.W., Kurth, W.S., Farrell, W.M., 2011. Characteristics of the dust-plasma interaction near Enceladus' South Pole. Plan. Space Sci. 59, 17-25.

Shah, M.B., Latimer, C.J., Montenegro, E.C., Tucker, O.J., Johnson, R.E., Smith, H.T., 2009. The Implantation and Interactions of $\mathrm{O}^{+}$in Titan's atmosphere: laboratory measurements of collision-induced dissociation of $\mathrm{N}_{2}$ and modeling of positive ion formation. Astrophys. J. 703, 1947-1954.

Simon, S., Saur, J., Kriegel, H., Neubauer, F.M., Motschmann, U., Dougherty, M.K. 2011. Influence of negatively charged plume grains and hemisphere coupling currents on the structure of Enceladus' Alfvén wings: analytical modeling of Cassini magnetometer observations. J. Geophys. Res. 116, 4221.

Sittler, E.C., Ali, A., Cooper, J.F., Hartle, R.E., Johnson, R.E., Coates, A.J., Young, D.T. 2009. Heavy ion formation in Titan's ionosphere: magnetospheric introduction of free oxygen and a source of Titan's aerosols? Plan. Space Sci. 57, 1547-1557.

Smith, H.T., Mitchell, D.G., Johnson, R.E., Paranicas, C.P., 2009. Investigation of energetic proton penetration in Titan's atmosphere using the Cassini INCA instrument. Plan. Space Sci. 57, 1538-1546.

Snowden, D., Yelle, R.V., 2014. The thermal structure of Titan's upper atmosphere II: energetics. Icarus 228, 64-77. 
Snowden, D., Yelle, R.V., Cui, J., Wahlund, J.E., Edberg, N.J.T., Ågren, K., 2013. The thermal structure of Titan's upper atmosphere, I: temperature profiles from Cassini INMS observations. Icarus 226, 552-582.

Soderblom, J.M., Barnes, J.W., Soderblom, L.A., Brown, R.H., Griffith, C.A., Nicholson, P.D., Stephan, K., Jaumann, R., Sotin, C., Baines, K.H., Buratti, B.J., Clark, R.N., 2012. Modeling specular reflections from hydrocarbon lakes on Titan. Icarus 220, 744-751.

Soderblom, J.M., Brown, R.H., Soderblom, L.A., Barnes, J.W., Jaumann, R., Mouélic, S.L. Sotin, C., Stephan, K., Baines, K.H., Buratti, B.J., Clark, R.N., Nicholson, P.D., 2010 Geology of the Selk crater region on Titan from Cassini VIMS observations. Icarus 208, 905-912.

Soderblom, L.A., Becker, T.L., Kieffer, S.W., Brown, R.H., Hansen, C.J., Johnson, T.V., Kirk, R.L., Shoemaker, E.M., Cook, A.F., 1990. Triton's geyser-like plumesdiscovery and basic characterization. Science 250, 410-415.

Soderblom, L.A., Tomasko, M.G., Archinal, B.A., Becker, T.L., Bushroe, M.W., Cook, D.A. Doose, L.R., Galuszka, D.M., Hare, T.M., Howington-Kraus, E., Karkoschka, E., Kirk, R L., Lunine, J.I., McFarlane, E.A., Redding, B.L., Rizk, B., Rosiek, M.R., See, C., Smith, P. H., 2007. Topography and geomorphology of the Huygens landing site on Titan. Plan. Space Sci. 55, 2015-2024.

Sohl, F, Solomonidou, A., Wagner, F.W., Coustenis, A., Hussmann, H., SchulzeMakuch, D., 2014. Structural and tidal models of Titan and inferences on cryovolcanism. J. Geophys. Res. 119, 1013-1036.

Solomonidou, A., Bampasidis, G., Hirtzig, M., Coustenis, A., Kyriakopoulos, K. St. Seymour, K., Bratsolis, E., Moussas, X., 2013. Morphotectonic features on Titan and their possible origin. Plan. Space Sci. 77, 104-117.

Sotin, C., Altwegg, K., Brown, R.H., Hand, K., Lunine, J.I., Soderblom, J., Spencer, J., Tortora, P., JET Team, 2011. JET: journey to Enceladus and Titan. In: Lunar and Planetary Institute Science Conference Abstracts, p. 1326

Spahn, F., Schmidt, J., Albers, N., Hörning, M., Makuch, M., Seiß, M., Kempf, S., Srama, R., Dikarev, V., Helfert, S., Moragas-Klostermeyer, G., Krivov, A.V., Sremčević, M., Tuzzolino, A.J., Economou, T., Grün, E., 2006. Cassini dus measurements at Enceladus and implications for the origin of the E ring Science 311, 1416-1418.

Spencer, J.R., Barr, A.C., Esposito, L.W., Helfenstein, P., Ingersoll, A.P., Jaumann, R. McKay, C.P., Nimmo, F., Waite, J.H., 2009. Enceladus: an active cryovolcanic satellite. In: Dougherty, M.K., Esposito, L.W., Krimigis, S.M. (Eds.), Saturn from Cassini-Huygens. Springer, New York, pp. 683-724.

Spencer, J.R., Howett, C.J.A., Verbiscer, A.J., Hurford, T.A., Segura, M.E., Pearl, J.C., 2011. High-resolution observations of thermal emission from the south pole of Enceladus. In: Lunar and Planetary Institute Science Conference Abstracts, p. 2553.

Spencer, J.R., Nimmo, F., 2013. Enceladus: an active ice world in the saturn system. Ann. Rev. Earth Planet. Sci. 41, 693-717.

Stephan, K., Jaumann, R., Brown, R.H., Soderblom, J.M., Soderblom, L.A., Barnes, J.W. Sotin, C., Griffith, C.A., Kirk, R.L., Baines, K.H., Buratti, B.J., Clark, R.N., Lytle, D.M. Nelson, R.M., Nicholson, P.D., 2010. Specular reflection on Titan: liquids in Kraken Mare. Geophys. Res. Lett. 37, 7104.

Stephan, K., Jaumann, R., Wagner, R., 2013. Geology of icy bodies. In: Gudipati, M.S. Castillo-Rogez, J. (Eds.), The Science of Solar System Ices. Springer, New York, pp. 279-367.

Stofan, E.R., Elachi, C., Lunine, J.I., Lorenz, R.D., Stiles, B., Mitchell, K.L., Ostro, S. Soderblom, L., Wood, C., Zebker, H., Wall, S., Janssen, M., Kirk, R., Lopes, R., Paganelli, F., Radebaugh, J., Wye, L., Anderson, Y., Allison, M., Boehmer, R. Callahan, P., Encrenaz, P., Flamini, E., Francescetti, G., Gim, Y., Hamilton, G. Hensley, S., Johnson, W.T.K., Kelleher, K., Muhleman, D., Paillou, P., Picardi, G., Posa, F., Roth, L., Seu, R., Shaffer, S., Vetrella, S., West, R., 2007. The lakes of Titan. Nature 445, 61-64.

Stofan, E.R., Lunine, J.I., Lorenz, R.D., Aharonson, O., Bierhaus, E., Clark, B., Griffith, C., Harri, A.M., Karkoschka, E., Kirk, R., Kantsiper, B., Mahaffy, P., Newman, C., Ravine, M., Trainer, M., Waite, H., Zarnecki, J., 2010. Exploring the seas of Titan: the Titan Mare Explorer (TiME) Mission. In: Lunar and Planetary Institute Science Conference Abstracts, p. 1236.

Strobel, D.F., 2009. Titan's hydrodynamically escaping atmosphere: escape rates and the structure of the exobase region. Icarus 202, 632-641.

Teanby, N.A., Irwin, P.G.J., de Kok, R., Jolly, A., Bézard, B., Nixon, C.A., Calcutt, S.B. 2009a. Titan's stratospheric $\mathrm{C}_{2} \mathrm{~N}_{2}, \mathrm{C}_{3} \mathrm{H}_{4}$, and $\mathrm{C}_{4} \mathrm{H}_{2}$ abundances from Cassini/CIRS far-infrared spectra. Icarus 202, 620-631.

Teanby, N.A., Irwin, P.G.J., de Kok, R., Nixon, C.A., 2009b. Dynamical implications of seasonal and spatial variations in Titan's stratospheric composition. Phil. Trans. R. Soc. Lond. A 367, 697-711.

Teanby, N.A., Irwin, P.G.J., de Kok, R., 2010a. Compositional evidence for Titan's stratospheric tilt. Plan. Space Sci. 58, 792-800.

Teanby, N.A., Irwin, P.G.J., de Kok, R., Nixon, C.A., 2010b. Seasonal changes in Titan's polar trace gas abundance observed by Cassini. Astrophys. J. 724, L84-L89.

Teanby, N.A., Irwin, P.G.J., Nixon, C.A., de Kok, R., Vinatier, S., Coustenis, A., SeftonNash, E., Calcutt, S.B., Flasar, F.M., 2012. Active upper-atmosphere chemistry and dynamics from polar circulation reversal on Titan. Nature 491, 732-735.

Teanby, N.A., de Kok, R., Irwin, P.G.J., Osprey, S., Vinatier, S., Gierasch, P.J., Read, P.L., Flasar, F.M., Conrath, B.J., Achterberg, R.K., Bezard, B., Nixon, C.A., Calcutt, S.B. 2008. Titan's winter polar vortex structure revealed by chemical tracers. J. Geophys. Res. 113, E12003.

Thomsen, M.F., Reisenfeld, D.B., Delapp, D.M., Tokar, R.L., Young, D.T., Crary, F.J. Sittler, E.C., McGraw, M.A., Williams, J.D., 2010. Survey of ion plasma parameters in Saturn's magnetosphere. J. Geophys. Res. 115, 10220.

Tinsley, T., Sarsfield, M., Rice, T., 2011. Alternative radioisotopes for heat and power sources. J. Br. Interplan. Soc. 64, 49-53.
Tobie, G., Gautier, D., Hersant, F., 2012. Titan's bulk composition constrained by Cassini-Huygens: implication for internal outgassing. Astrophys. J. 752, 125.

Tobie, G., Lunine, J.I., Monteux, J., Mousis, O., Nimmo, F., 2014. The origin and evolution of Titan. In: Müller-Wodarg, I., Griffith, C.A., Lellouch, E., Cravens, T.E. (Eds.), Titan: Interior, Surface, Atmosphere, and Space Environment. Cambridge University Press, Cambridge, pp. 29-62.

Tobie, G., Lunine, J.I., Sotin, C., 2006. Episodic outgassing as the origin of atmospheric methane on Titan. Nature 440, 61-64.

Tobie, G., Čadek, O., Sotin, C., 2008. Solid tidal friction above a liquid water reservoir as the origin of the south pole hotspot on Enceladus. Icarus 196, 642-652.

Tokar, R.L., Johnson, R.E., Hill, T.W., Pontius, D.H., Kurth, W.S., Crary, F.J., Young, D.T., Thomsen, M.F., Reisenfeld, D.B., Coates, A.J., Lewis, G.R., Sittler, E.C., Gurnett, D.A., 2006. The interaction of the atmosphere of Enceladus with Saturn's plasma. Science 311, 1409-1412.

Tokar, R.L., Johnson, R.E., Thomsen, M.F., Wilson, R.J., Young, D.T., Crary, F.J., Coates, A.J., Jones, G.H., Paty, C.S., 2009. Cassini detection of Enceladus' cold water-group plume ionosphere. Geophys. Res. Lett. 36, 13203.

Tokar, R.L., Wilson, R.J., Johnson, R.E., Henderson, M.G., Thomsen, M.F., Cowee, M.M., Sittler, E.C., Young, D.T., Crary, F.J., McAndrews, H.J., Smith, H.T., 2008. Cassini detection of water-group pick-up ions in the Enceladus torus. Geophys. Res. Lett. 35, 14202.

Tomasko, M.G., Archinal, B., Becker, T., Bézard, B., Bushroe, M., Combes, M., Cook, D., Coustenis, A., de Bergh, C., Dafoe, L.E., Doose, L., Douté, S., Eibl, A., Engel, S., Gliem, F., Grieger, B., Holso, K., Howington-Kraus, E., Karkoschka, E., Keller, H.U., Kirk, R., Kramm, R., Küppers, M., Lanagan, P., Lellouch, E., Lemmon, M., Lunine, J., McFarlane, E., Moores, J., Prout, G.M., Rizk, B., Rosiek, M., Rueffer, P., Schröder, S.E., Schmitt, B., See, C., Smith, P., Soderblom, L., Thomas, N., West, R., 2005. Rain, winds and haze during the Huygens probe's descent to Titan's surface. Nature 438, 765-778.

Turtle, E.P., Perry, J.E., Hayes, A.G., Lorenz, R.D., Barnes, J.W., McEwen, A.S., West, R.A. Del Genio, A.D., Barbara, J.M., Lunine, J.I., Schaller, E.L., Ray, T.L., Lopes, R.M.C. Stofan, E.R., 2011. Rapid and extensive surface changes near Titan's equator: evidence of April showers. Science 331, 1414-1417.

Ventura, B., Notarnicola, C. Casarano, D., Posa, F., Hayes, A.G., Wye, L., 2012. Electromagnetic models and inversion techniques for Titan's Ontario Lacus depth estimation from Cassini RADAR data. Icarus 221, 960-969.

Wahlund, J.E., André, M., Eriksson, A.I.E., Lundberg, M., Morooka, M.W., Shafiq, M., Averkamp, T.F., Gurnett, D.A., Hospodarsky, G.B., Kurth, W.S., Jacobsen, K.S., Pedersen, A., Farrell, W., Ratynskaia, S., Piskunov, N., 2009. Detection of dusty plasma near the E-ring of Saturn. Plan. Space Sci. 57, 1795-1806.

Waite, J.H., Brockwell, T., Elliot, J., Reh, K., Spencer, J., Outer Planets Satellites Decadal Subpanel, 2010. Titan lake probe: the ongoing NASA decadal study preliminary report. In: EGU General Assembly Conference Abstracts, p. 14762.

Waite, J.H., Combi, M.R., Ip, W.H., Cravens, T.E., McNutt, R.L., Kasprzak, W., Yelle, R. Luhmann, J., Niemann, H., Gell, D., Magee, B., Fletcher, G., Lunine, J., Tseng, W.L., 2006. Cassini ion and neutral mass spectrometer: Enceladus plume composition and structure. Science 311, 1419-1422.

Waite, J.H., Magee, B., Brockwell, T., 2011. The effect of flyby velocity on the composition of the Enceladus gas torus as measured by Cassini INMS. In: Lunar and Planetary Institute Science Conference Abstracts, p. 2818.

Waite, J.H., Niemann, H., Yelle, R.V., Kasprzak, W.T., Cravens, T.E., Luhmann, J.G., McNutt, R.L., Ip, W.H., Gell, D., De La Haye, V., Müller-Wordag, I., Magee, B., Borggren, N., Ledvina, S., Fletcher, G., Walter, E., Miller, R., Scherer, S., Thorpe, R., Xu, J., Block, B., Arnett, K., 2005. Ion neutral mass spectrometer results from the first Flyby of Titan. Science 308, 982-986.

Waite, J.H., Young, D.T., Cravens, T.E., Coates, A.J., Crary, F.J., Magee, B., Westlake, J., 2007. The process of Tholin formation in Titan's upper atmosphere. Science 316, 870

Waite Jr., J.H., Lewis, W.S., Magee, B.A., Lunine, J.I., McKinnon, W.B., Glein, C.R., Mousis, O., Young, D.T., Brockwell, T., Westlake, J., Nguyen, M.J., Teolis, B.D., Niemann, H.B., McNutt, R.L., Perry, M., Ip, W.H., 2009. Liquid water on Enceladus from observations of ammonia and ${ }^{40} \mathrm{Ar}$ in the plume. Nature 460, 487-490.

West, R.A., Balloch, J., Dumont, P., Lavvas, P., Lorenz, R., Rannou, P., Ray, T., Turtle, E.P., 2011. The evolution of Titan's detached haze layer near equinox in 2009. Geophys. Res. Lett. 38, 6204.

Westlake, J.H., Bell, J.M., Waite Jr., J.H., Johnson, R.E., Luhmann, J.G., Mandt, K.E., Magee, B.A., Rymer, A.M., 2011. Titan's thermospheric response to various plasma environments. J. Geophys. Res. 116, 3318.

Westlake, J.H., Waite, J.H., Carrasco, N., Richard, M., Cravens, T., 2014. The role of ion-molecule reactions in the growth of heavy ions in Titan's ionosphere. J. Geophys. Res. 119, 5951-5963.

Wood, C.A., Lorenz, R., Kirk, R., Lopes, R., Mitchell, K., Stofan, E., Cassini Radar Team, 2010. Impact craters on Titan. Icarus 206, 334-344.

Yelle, R.V., Cui, J., Müller-Wodarg, I.C.F., 2008. Methane escape from Titan's atmosphere. J. Geophys. Res. 113, 10003.

Yung Y.L. Allen, M. Pinto, J.P. 1984 Photochemistry of the atmosphere of Titancomparison between model and observations. Astrophys. J. Suppl. 55, 465-506.

Zebker, H., Hayes, A., Janssen, M., Le Gall, A., Lorenz, R., Wye, L., 2014. Surface of Ligeia Mare, Titan, from Cassini altimeter and radiometer analysis. Geophys. Res. Lett. 41, 308-313.

Zolotov, M.Y., 2007. An oceanic composition on early and today's Enceladus. Geophys. Res. Lett. 34, 23203.

Zolotov, M.Y., Tobie, G., Postberg, F., Magee, B., Waite, J.H., Esposito, L., 2011. Chemical and phase composition of Enceladus: insights from Cassini data. In: EPSC-DPS Joint Meeting 2011, p. 1330 